\title{
Growth Factors \& Stem Cells Entrapment in Bio Compatible \& Biodegradable Nano Particles to Prevent Early Degradation \& Facilitate Gradual Release
}

ANURUDDHA A. H. M. P. ( $\sim$ dranuruddha123@gmail.com )

University of Colombo

C. A. N. FERNANDO

Wayamba University of Sri Lanka

YOSHIHISA SAIDA

Toho University Ohashi Medical Center

MINORU SAKURABA

Iwate Medical University

\section{Research Article}

Keywords: growth factors, stem cells, core treating agents, Solid Lipid Nano Particles (SLNP)

Posted Date: March 11th, 2021

DOl: https://doi.org/10.21203/rs.3.rs-275678/v1

License: (c) (1) This work is licensed under a Creative Commons Attribution 4.0 International License.

Read Full License 


\title{
GROWTH FACTORS \& STEM CELLS ENTRAPMENT IN BIO COMPATIBLE \& BIODEGRADABLE NANO PARTICLES TO PREVENT EARLY DEGRADATION \& FACILITATE GRADUAL RELEASE
}

\author{
*A. H. M. P. ANURUDDHA
}

MBBS (Faculty of Medicine at the University of Kelaniya), MD (Faculty of Medicine, University of Colombo), MRCS England, Member of Royal College of Surgeons, SLMC REG 18578

dranuruddha123@gmail.com / Tel: +94714908059

\section{A. N. FERNANDO}

Senior Professor of Nanoscience technology/Head/Chair, Department of Nanoscience technology, Faculty of technology Wayamba University of Sri Lanka, Kuliyapitiya

canfernando9@wyb.ac.lk/Tel: +94718102414

\section{YOSHIHISA SAIDA}

M.D., PH.D., Chief Professor, Dep. of Surgery, Vice Hospital President, Chief of Medical Safety Management Office Toho University Ohashi Medical Center, 2-22-36 Ohashi Meguro-ku Tokyo 153-8515, Japan

yoshisaida@nifty.com / Tel: +81-3-3468-1251 / Fax: +81-3-5433-3091

\section{MINORU SAKURABA}

M.D., Ph.D., Professor Department of Plastic and Reconstructive Surgery, Iwate Medical University, 2-1-1 Idaidori, Yahaba-cho, Shiwa, Iwate, 028-3695, Japan

msakurab@iwate-med.ac.jp / Tel: +81-19-613-7111 / Fax: +81-19-907-6648 


\section{COMPETING INTEREST STATEMENT}

I declare that I have no significant competing financial, professional, or personal interests that might have influenced the performance or presentation of the work described in this manuscript. I am currently working as a consultant general surgeon at Wijaya Kumaratunga Memorial Hospital, Seeduwa Sri Lanka and at Nawaloka Hospital, Negombo Sri Lanka. I declare that my current service does not depend on the research but is done entirely benefitting my personal interest and higher education carried out in the field of Nano Technology under the department of Nanoscience Technology at the Wayamba University of Sri Lanka. Further I would like to state that the device introduced through the research can be of use in the industry as patent has been obtained for the design initially. My interest in publishing this article also is that the medical field may make use of future ventures in finding more feasible and efficient ways in treating people through nanoscience.

\section{ETHICS STATEMENT}

The study was approved by the National Science foundation of Sri Lanka. All the participants provided the informed consent. The study was conducted in accordance with the relevant guidelines and codes of ethics of the National Nanotechnology Policy and the ethics under the Medical Research Institute Sri Lanka (MRI). The study also is done in accordance to the codes of ethics adopted by the 18th WMA General Assembly, Helsinki, Finland, June 1964 and amended by the: 29th WMA General Assembly, Tokyo, Japan, October 1975 35th WMA General Assembly, Venice, Italy, October 1983 41st WMA General Assembly, Hong Kong, September 1989 48th WMA General Assembly, Somerset West, Republic of South Africa, October 1996 52nd WMA General Assembly, Edinburgh, Scotland, October 2000 53rd WMA General Assembly, Washington DC, USA, October 2002 (Note of Clarification added) 55th WMA General Assembly, Tokyo, Japan, October 2004 (Note of Clarification added) 59th WMA General Assembly, Seoul, Republic of Korea, October 2008 64th WMA General Assembly, Fortaleza, Brazil, October 2013.

\section{FIGURE LEGENED}

\begin{tabular}{|l|l|l|}
\hline $\begin{array}{l}\text { Figure } \\
\text { Number }\end{array}$ & Description & $\begin{array}{l}\text { Page } \\
\text { Number }\end{array}$ \\
\hline Figure 1 & Hypothetical structure of Liposomic structural Solid Lipid Nano Particle & 05 \\
\hline Figure 2 & Invented devise (line diagram) & 06 \\
\hline Figure 3 & Process of mixing & 11 \\
\hline Figure 4 & SEM cross sectional image of Dolomite composition & 12 \\
\hline Figure 5 & SEM cross sectional image of composition variation at $965^{\circ}$ C & 12 \\
\hline Figure 6 & SEM image of composition at increased temperature & 13 \\
\hline Figure 7 & SEM image: Cross section of final material & 13 \\
\hline Figure 8 & SEM image: Surface Area of final & 15 \\
\hline Figure 9 & XRD image of final compound & 15 \\
\hline Figure 10 & SEM images of composition at higher temperatures & \\
\hline
\end{tabular}




\section{GROWTH FACTORS \& STEM CELLS ENTRAPMENT IN BIO COMPATIBLE \& BIODEGRADABLE NANO PARTICLES TO PREVENT EARLY DEGRADATION \& FACILITATE GRADUAL RELEASE}

\section{ABSTRACT}

The use of growth factors and stem cells as the core treating agents is one step into creating a biocompatible Solid Lipid Nano Particles (SLNP) for treatments. Apart from obtaining these growth factors and stem cells from the patients, using the bi-product of the extraction process which is the lipid of the patient for the production of the SLNP assures the final product to be biocompatible and of a unique structure. The use of autologous cells and proteins from the patients makes the entire process medically ethical and more viable for treatment procedures. This article, thus discusses on the experimental process of developing such SLNP and the introduction of the relevant medical contraption designed uniquely for the procedure inclusive of a specified membrane.

\section{INTRODUCTION}

\section{The invention of the device}

The device was conceptualized with the initial goal of keeping the design manufacturing procedures as simple as possible. Providing a quality and durable product maintaining the cost at an affordable rate was also a key focus in the design process. Thus, materials common and already certified for applications in the medical field were utilized for the project. Thereby the device could be certified as biocompatible. The device design focused on creating compartments necessary for the formation of Solid Lipid Nano Particles (SLNP), the process to mix the SLNP formed with the treatment materials, and a final extraction for relevant applications.

\section{The development of a unique membrane}

As the study focuses on creating SLNP which can be categorized as biodegradable and biocompatible, the filtration process to obtaining these SLNP is considered an important step. The filtration and extraction are to be done from body fat thereby the procedure should be of preciseness, good hygiene as well as adhering to the environmental conditions suitable for the procedure. As the outcome of the SLNP Solid Lipid Nano Particle will be used for the formation of Lysosomes to be induced in treatments directly, it is mandatory to maintain form, size and quality consistency in the final outcome. In order to assure that the desired and effective characteristics can be created consistently when needed while considering specifications also features and characteristics of ceramic membranes in the market were analyzed. As the existing membranes could not achieve the requirements a specific membrane for the filtration process was designed.

Membrane characterization analyzed through Scanning Electron Microscopy (SEM)/ X-ray diffraction (XRD)/ Specific Gravity etc.

In the process of designing the new membrane, the suitability of the application of Quartz and mixing it with another pore -forming agent such as dolomite for the final material were studied through various procedures. The experiments were done to observe the quality and characteristics of the final membrane based on the outlined requirements. The material composition was altered and analyzed to find the most fit membrane material that could be used. The SEM and XRD tests were done to observe the material characteristics in detail thus enabling the analysis of pore sizes, distribution, porosity, strength of membrane and such characteristics. Verifying such prominent characteristics made the designed membrane more accurate and durable. 


\section{Production of SLNP with a range of dimensions}

Varying the materials, temperature and other elements mixed with the core material of the membrane enabled the formation of the desired SLNP size through the designed permeable membrane. The analysis was done by altering materials and temperature also provided knowledge on possibilities of creating SLNP within a varied size range. With changes done through the study three main categories of SLNP sizes were identified where the size ranged from $50 \mu \mathrm{nm}$ up to the larger size of $400 \mu \mathrm{nm}$.

\section{Autologous component (Stem Cells/ Growth Factors/ Human lipids as biproducts)}

The highlight of the overall study is the formation of the desired Lysosomic Liposome structure for treatment procedures. The final product consists of the extracted SLNP particles as well as the stem cells and growth factors obtained from the patients which are all in all the autologous components in the final product. It should be noted that even the SLNP are formed from the lipids obtained as the bi products in the process of extracting the stem cells from the patients. Therefore $95 \%$ of the entire composition will be of autologous components. The effectiveness and value of using autologous components will be discussed in detail in the latter part of the article.

\section{METHOD}

\section{Application of Surfactants instead of Chemical Substances}

In the process of mixing all components and forming the final treatment cell, no harmful chemical is used. Only non-ionic surfactants that are unharmful are used to enhance the emulsification process of the component. And phospholipids are being used as the surfactants to avoid any application of any strong or harmful chemical substances that could create any side effects to the patient. Therefore, the entire treatment cell produced can be considered to be free of external and any harmful chemical substance. Based on the materials used and their bio compatibility the final substance can be easily categorized as biocompatible and ethical for the application for human beings. The necessary samples were obtained by a volunteered patient of mine who went under the surgery for an abdominoplasty. As the surgery provided with a considerable amount of body fat that was to be discarded, along with the patients consent the samples were obtained for necessary experimental analysis of the formation of desired SLNP. Further note that the process of obtaining the samples was under aligned ethical codes of the National Nanotechnology Policy of the National Science foundation of Sri Lanka. The material production for the device was done at the University of Moratuwa, Department of Materials Science and Engineering under the relevant ethics and regulations. The analyzed data which is represented was conducted within the premises under required standardized conditions.

\section{Mechanical filtration and the Mixing Procedures}

In the process of forming the final product, the initial component formed mechanically is the SLNP. By undergoing a mechanical filtration process through compression, the applicable lipid substances can be extracted as SLNP through the unique designed ceramic membrane.

In the device designed the filtration is done within the first compartment. The walls of the barrel in which the lipid is to be placed for compression are lined with the unique ceramic permeable membrane also designed specifically for this procedure. Details of the membrane are further discussed later on, in this article. Its function remains simple.

The obtained SLNP thus will fall into the larger barrel within which the first barrel where the filtration of the lipids was processed. The larger barrel is also where the aqueous medium consisting of surfactants, growth factors, and stem cells will be introduced. As most of the particles thus formed could yet retain on the outer 
walls of the filtering membrane the device is made so that the medical personal handling it could simply shake the device a few times to assure that the final mixing procedure is completed. Thus, through a simple process of emulsification, the particles combine to form the final structure.

\section{Final Expected Product of Liposomes}

The final structure of the Liposomes consists of a hydrophilic core and a hydrophobic bilayer (Gunay, 2018; Ozer, 2018). The aqueous solution consisting stem cells and growth factors becomes the aqueous volume entrapped at the core of the Liposomes. Based on the hypothetical analysis the phospholipids consisting the hydrophobic tails and hydrophilic heads form the bilayers within the Liposome creating hydrophobic and hydrophilic environments surrounding the aqueous core. The actual Liposomic structure is yet under investigation and the hypothetical diagram is depicted herewith in figure 1.

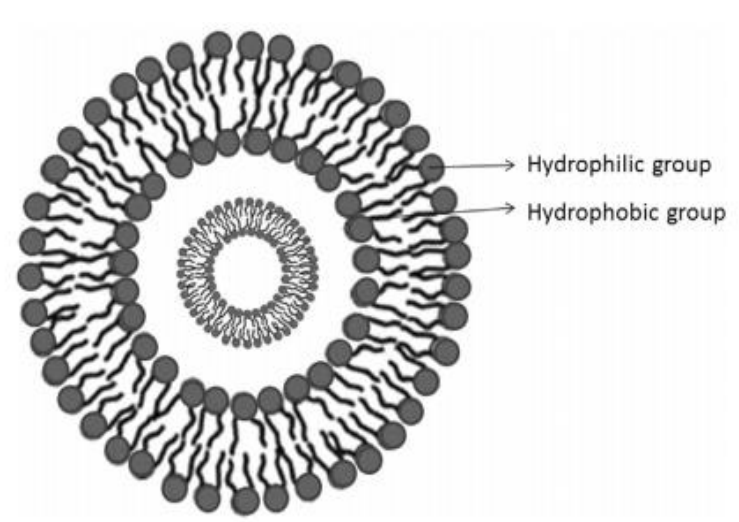

Figure 1 - Hypothetical structure of Liposomic structural Solid Lipid Nano Particle

The SLNP will then penetrate the formed Liposome structures filling in the gaps within the hydrophobic layers concealing the structure. The entrapped aqueous solution is thereby well protected for a longer period providing better control on treatment procedures. The phospholipid structure consisting of bilayers of protection and a core which can be considered as its innermost environment makes the liposomes biocompatible. Simple degradation avoiding any toxic and immunogenic effects enables to create a superior value in the final product. Though the procedure sounds intricate with many steps involved the outlined suggested process would take only a short time with a minimum amount of procedures and less complicated measures taken based on the designed device functionality tested.

\section{A Closed System Treatment That Is Cost-Effective and Less Time Consuming}

Based on the research done the overall process would take about 2-3 hours for all procedures. And one of the highlights of this procedure is that multiple procedures can be done simultaneously reducing the time taken and effort in the overall process than the usual. As discussed within the research most Stem Cell and Growth Factor treatments are done through intricate procedures that consume many steps, many hours and even requires storage in certain methods. This makes such treatments readily unavailable for most patients and unaffordable for patients as well as expensive for the providers. But, as a turnover with the upcoming demand in cell therapies in the medical industry this report provides evidence for easier, cost effective and a readily available procedure.

Obtaining the suitable components of the human lipid and the mixing procedure of all elements to complete the final process of forming the final cell a specified appliance is needed. The introduced device can achieve the targets and subsequently inject the final product for treatment in a matter of seconds, making it applicable at that instant for the patients. The coating created from the SLNP will help increase the lifetime of the Growth Factors and Stem cells which in existing scenarios are environments that cannot be controlled (Ho et al., 2016) thus reducing the cell lifetime in general procedures to half of what can be provided through the new method introduced. Being a closed system, a minimum contamination possibility is identified.

The simple structure of the device introduced thus can create a step forward in the medical industry. Creating an almost effortless, yet effective and affordable device for the subsequent treatment procedure introduced. As the materials used for its production are readily available and not of the high cost. The procedure being simple steps will allow the process to take minimum time to complete the treatment. 


\section{Further study opens possibility in the application for treating systematic illness}

Designing a new membrane that is medically ethical and biocompatible as well as cost-effective while achieving other unique specifications created an opening on studies of what the membrane could be used for. As of now the device designed will only allow to treat open wounds but with further detailed studies on the Liposomic structure treatment methods for systematic illnesses can be achieved. With suitable alterations and improvements on the structure application of the final product can be expected to lie within a wider range with further studies provided.

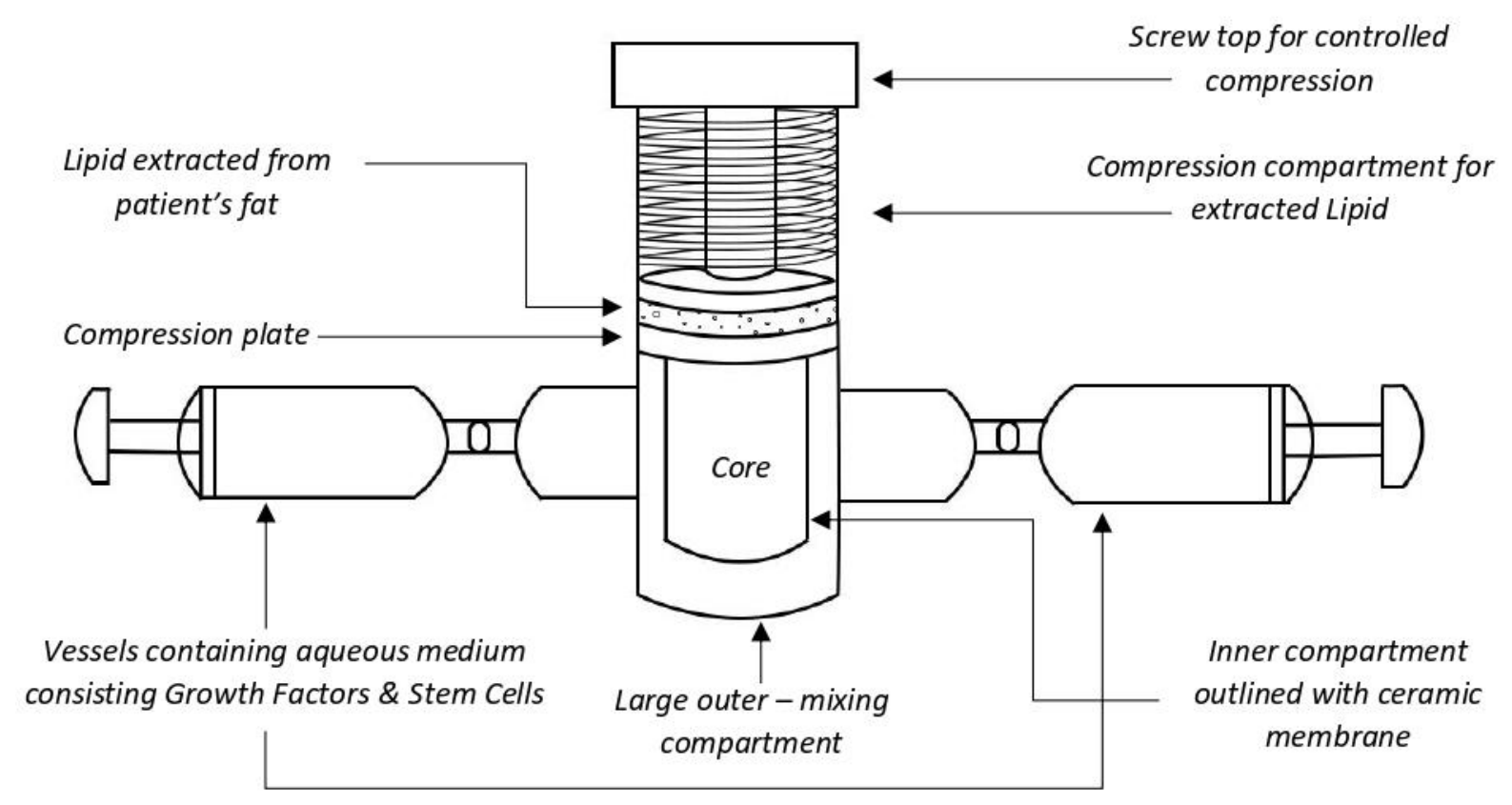

Figure 2 - Invented devise (line diagram)

\section{RESULTS}

\section{The Invention of the Device and its Functionality}

The device as explained was designed so as to create a simple system where several procedures can be done simultaneously in the simplest manner possible. Therefore, the invention was designed as in the structure below.

Based on the outlined structure in figure 2 above, it can be identified that the device consists of a closely relatable structure of two syringes combined. The raw material of the compartments used or compression and mixing are designed with the application of polypropylene which is used for the production of syringes. Yet an interesting design tactic was applied, to convert the usual plunger of the syringe into a screw. This was done so as to increase the control over the compression filtration process of the extracted lipids. Thus, a more uniform product of SLNP could be obtained through the device. Intricate details as such were clarified by experimental and trial-based procedures.

The compression compartment is where the obtained lipids as a bi-product of the adipose-derived stem cells from the patient are being pressed for filtration.

The walls of the barrel in which the lipid is placed for compression is lined with the unique ceramic permeable membrane also designed specifically for this procedure. Details of the membrane are further discussed later 
on in this article. Its function remains simple. As it acts as the main filtering membrane through which the desired SLNP should be filtered.

The obtained SLNP thus falls into the larger barrel within which the first barrel where the filtration of the lipids was processed. The larger barrel is also where the aqueous medium consisting of surfactants, growth factors, and stem cells are introduced. It initially acts as a collection chamber of the formed SLNP.

As most of the particles thus formed could yet retain on the outer walls of the filtering membrane the device is made so that the medical personal handling it could simply shake the device a few times so as to assure that the final mixing procedure is completed. And specified expertise will not be needed to operate the device for the procedures. This eases the use of the device enabling the procedure to be done at minimum experience but with necessary guidance at initial stages. Once observed, within a theatre system the device can be operated and the treatment can be performed by an individual due to the simplicity of the device and procedure.

Research and experiments have provided satisfactory results of the final product obtained. Thus, the simple process of compressing and mixing the elements to obtain the final treatment cells can be considered as successful. The functionality of the device itself presents the ease of use of the equipment and the speed of treatment procedures.

Another highlight of the device and its design can be considered as the protection of the highly sensitive growth factors and stem cells used with the closed system structure. As these cells once within the device will not be in contact with the external environment unless it is coasted with the protective layers and the final Lysosome structure is obtained ready for treatment. The entire procedure therefore can be considered to be one that cycles from patient to device and directly back to the relevant patient. The simplicity and the high efficiency of the device functionality itself draw the benchmark for this unique innovation.

The device is built as a single disposable unit. The low cost for the production therefore enables the usage of a new unit per patient. This increases the hygiene in the treatment procedure. The cost of the production of the membrane used in the device was also controlled and built in a manner that it can be affordable. The overall production procedure even in stages of producing the membrane was identified as low cost. The entire device was estimated to be of low cost and can be provided to the public at affordable rates allowing any patient to receive the treatment.

\section{Unique Membrane Designed}

Membranes used for microfiltration purposes in the medical field are generally composites, symmetric, or asymmetric which are fabricated from polymeric or inorganic materials (Hogan B., Breiter S., 2006). Such membranes are usually made from ceramic which can be fabricated by classical techniques through fabrication, sol-gel techniques or by employing alkoxides. Such filtration procedures have shown several flaws that were mandatory to be avoided for this purpose. Most studies have been done on permeable ceramic membranes where the permeability has been achieved by mixing a certain ratio of clay and starch (Youmoue et al., 2017). The disadvantage in such membranes made by mixing the regular materials is that the pore size cannot be controlled as desired and would rather have a fixed range of pore formation with other relevant variables given (Yakub et al., 2012). Therefore ceramic membranes were studied to clarify the exact characteristics to be improved to create the suitable membrane for the membrane contactor process, to produce the SLNP. 


\section{Porous Ceramic Membranes Used}

Within the existing industry of medicine, microfiltration is mostly done with the use of ceramic porous membranes. The pores are generally formed with the help of a pore-forming agent such as sawdust or starch (Abd Aziz et al., 2019). Such membranes are made with materials that consist of good chemical stability. The use of ceramic as the core ingredient prevents in causing any corrosive condition in the process of using the membrane (Ben Ali et al., 2018). This is a must to be considered especially in medical applications. The strength and rigidity are also mandatory characteristics maintained in general to increase the durability of a membrane manufactured. The question thereby arises as to why the already designed ceramic membranes cannot be used for the extraction of SLNP in the introduced process of the stem cell and growth factor treatment.

\section{Requirements in Specified Membrane}

One of the main issues in the existing ceramic permeable membranes is the variation of the pore sizes, the inconsistency throughout the surface (Youmoue et al., 2017). The challenge was to identify a pore-forming agent where its chemical reactivity and the reacting characteristics can be controlled as desired as the poreforming agents were found to be the cause of this inconsistency observed. The final membrane designed needed to be bio compatible, and the overall production was to be framed at a reasonable cost so that it will not affect the final designed device production. The device and membrane were designed to be used per individual patient therefore mass production were considered and the easiest methods for production was studied experimentally. The distribution of the pores in the permeable membrane was an essential focus as this would overall affect the treatment procedure. Varied pore sized will not allow to create uniform-sized SLNP which will not be effective in the successive steps. Therefore, evenly distributed pores with a specific dimension were required to be maintained.

\section{Material Selection}

Referring to chemical engineering industry studies, the mineral Quartz was identified as a potential poreforming agent for the inventive membrane. The raw material itself depicted characteristics that were required (Peng \& Redfern, 2013) and desirable as per the initial study. Through various experimental procedures, the material was studied and determined as the best-fit pore-forming agent applicable. The structural and chemical stability of Quartz as a material as well as its behavior based on temperature differentiations (Rosenbrand, n.d.) were noted as desirable and supportive in the process of creating a suitable pore size. Further, the study developed into interesting levels wherein the process of studying the pore-forming process of Quartz in ceramic it was discovered that the pore shape can be controlled and a much desirable conical shape can be formed which could enhance the overall filtration procedure of the final system.

This article introduces Quartz as a pore-forming agent with specifications that can be considered as a medical advancement useful for generations to come. The suitability in the application of Quartz as the pore-forming agent is studied based on experiments done on its; chemical stability (Kilikoglou et al., 1998), structural and chemical behavior with the temperature difference, material phase changes due to temperature (Peng \& Redfern, 2013) and also the material strength and the fineness of the final product and applicability in the prescribed medical procedures. 


\section{Raw Material Qualities and Characteristics}

In general, the average grain size of Quartz starts of their sedimentary history from around $0.6 \mathrm{~mm}$ with about $40 \%$ mono-crystalline grains. Quartz is porous media that consist of solids and pores. The porosity is the ratio of the volume of pores to that of the bulk volume. The behavior and structure of such pores can be studied through the study of the porosity of the material. For this, the volumetric flow rate based on Darcy's law (1856) is applied in general. Darcy's law states that the flow rate depends on fluid viscosity; thus, for a general fluid, flow can be expressed through the equation given below.

$$
q=\frac{Q}{A}=\frac{k}{\mu} \Delta P
$$

$\Delta \mathrm{P}:$ the pressure gradient

$\mathrm{q}:$ the specific discharge, henceforth referred to as the flow rate

$\mathrm{Q}$ : the volumetric flow rate

A : the cross-sectional area perpendicular to

$\mu$ : the dynamic viscosity of the fluid

$\mathrm{k}$ : the permeability

The porosity, therefore, is the volume of the cylindrical capillaries normalized by the bulk volume. Thus, the permeability can also be expressed in terms of the pore size and porosity. Likewise, the pore size can be defined using the equation for permeability as given below (Rosenbrand, n.d.).

$$
k=\frac{1}{8} r_{p}^{2} \emptyset
$$

As per the findings of Berryman and Blair (1987) Quartz is generally modeled with the use of the Kozney (1927) equation. The equation is stated below,

$$
q=\frac{Q}{A}=\frac{1}{\mu} \frac{c_{0} \emptyset^{3}}{S^{2}} \Delta P
$$

Through research done based on all data collected it is clarified that in Quartz the permeability is generally controlled due to the smaller pores existing within its structure. The larger intergranular pores are connected through the smaller pores which helps to limit the flow rate in larger pores. Therefore, the higher permeability in these pores would have a dominant effect on the measured permeability.

\section{$\alpha$ QUARTZ - $\beta$ QUARTZ Phase Transitions}

The $\alpha-\beta$ Quartz phase transition is categorized as a transition of the second order. This transition has been defined by many researches to be an order to disorder transformation (Spearing et al., n.d.). As used in many occasions the Landau theory along with the use of ab initio molecular dynamics are used in this experimental observation. This experiment was done to obtain a qualitative description of the macroscopic behavior of the Quartz phase transition.

The macroscopic behavior of the $\alpha-\beta$ phase transition is observed through the experiment done using the Landau Theory. The transition that occurs usually is where the $\beta$-quartz changes into the $\alpha$-quartz through 
the $\mathrm{SiO} 4$ tetrahedral structure rotations given that there are minimal distortions. Though the Landau theory assures clear results for displacing transition as the microscopic mechanism for the phase transition are not clear and accurate molecular dynamics are used in order to clarify this phase of the material. The experiment did pave the way to explore the effects of phase transition on dielectric properties as well. The atomic displacements in different directions during the phase transition where the temperature is accurately estimated from the calculated structural parameters based on ab initio molecular dynamics were also observed. It has been observed through experimental findings that during phase transitions the temperature of Quartz change within wide ranges (Xie et al., 2012).

At the phase transition point, the temperature reaches high degrees during which the dielectric behaviors of Quartz are observed. Results have been obtained depicting that the dielectric behaviors of Quartz are affected due to the phase transition (HnrvrrNcwlv, n.d.). In order to observe the phase transitions clearly and quantitatively calculate the properties dependant on the transition phases in quartz, thus the addition molecular dynamics simulations were carried out. The dielectric properties were measured with the initial temperature starting at room temperature. Thus, it was observed that at room temperature Quartz appeared at the $\alpha$ state and when the temperature increased it changed into the $\beta$ phase. Thereby it is clearly derived that the phase transition occurs as a result of the change in temperature (increasing from room temperature to a higher degree).

\section{The Structural Stability of natural Quartz}

Compared with most other primary minerals Quartz is found in abundance and consists of relative mechanical and chemical stability. Due to the existing greater specific surface of fine silt and clay-sized particles Quartz when obtained in fine grain size can be more reactive to the sedimentary geochemical environment. (Stevens, 1991)

Discussing the chemical stability and chemical nature of Quartz which is a compound made with one-part silicon and two parts of Oxygen ( $\mathrm{SiO} 2$ ) at room temperature it is almost inert and therefore does not react with any other substance. The chemical composition of Quartz which was found by a Swedish chemist named JönsJakob Berzelius in 1823 shows that the Si-O bond strength is very high and for this reason shows a low reactivity in any instance. This can be proved by studying the chemical and macromolecular structure and characteristics of the compound. (A.C. Akhavan 2005-2013)

\section{The Chemical Stability of natural Quartz}

Quartz is also derived as anhydrite of acid itself (orthosilicic acid, H4SiO4). Except for the reaction with hydrofluoric acid Quartz in general cannot be attacked by any other acid. On the other hand, the reaction of Quartz with alkaline substances will depend on the modification and crystal size of the material. Where amorphous quartz will readily dissolve at room temperature and crystalline Quartz will dissolve very slowly in hot watery alkaline solutions. It is observed also that Quartz acts as an acid in many geological environments and therefore reacts with many alkaline minerals but as stated previously the reaction rate depends and at times can be considered as almost not reacting.

The chemical stability of Quartz in water depends on several factors. These factors can be listed out as the temperature, pressure, surface structure of Quartz, and its structural

\begin{tabular}{|c|c|}
\hline SUBSTANCE & $\begin{array}{c}\text { SOLUBILITY IN } \\
\text { WATER AT 25 }\end{array}$ \\
\hline Macrocrystalline Quartz & $\begin{array}{c}2.9 \mathrm{mg} / \mathrm{l} / 6-11 \\
\mathrm{mg} / \mathrm{l}\end{array}$ \\
\hline Chalcedony & $22-34 \mathrm{mg} / \mathrm{l}$ \\
\hline Cristobalite & $6 \mathrm{mg} / \mathrm{l}$ \\
\hline Tridymite & $4.5 \mathrm{mg} / \mathrm{l}$ \\
\hline Stishovite & $11 \mathrm{mg} / \mathrm{l}$ \\
\hline
\end{tabular}

Table 1 - solubility of Quartz 
modification. At room temperature and given that pressure is maintained at normal levels the solubility of Quartz can be understood by the table 1 (Rykart,1995 \& Holleman,1985).

Thus, regarding the data given in the table above, at room temperature it is noted that Quartz is practically insoluble in water. But, the solubility of Quartz can increase at temperatures above $100^{\circ} \mathrm{C}$ and high pressures. And at $300^{\circ} \mathrm{C}$ depending on the pressure the solubility of Quartz in water is between 700 and $1200 \mathrm{mg} / \mathrm{l}$. Considering the structure of Quartz, it can be noted as a three-dimensional network of interconnected SiO4 tetrahedra. The overall crystal structure of Quartz is of a complex model. The angles and distances of $\alpha$ Quartz and $\beta$-Quartz structures are given in the table 2 (Hollemann\&Wiberg, 1985 and Rykart,1995) below.

\begin{tabular}{|c|c|c|}
\hline Modification & $\begin{array}{c}\text { Si-O-Si } \\
\text { Angle }\end{array}$ & $\begin{array}{c}\text { Si-O } \\
\text { Distance / } \\
\text { nm }\end{array}$ \\
\hline$\alpha$-Quartz & $144^{\circ}$ & $\begin{array}{c}0.16101- \\
143.6^{\circ}\end{array}$ \\
\hline$\beta$-Quartz & $153^{\circ}$ & 0.16145 \\
& & 0.1609 \\
\hline
\end{tabular}

Table 2 - Structure of Quartz

As the $\mathrm{Si}-\mathrm{O}$ bond is highly polar the $\mathrm{Si}-\mathrm{O}-\mathrm{Si}$ angle is more open. Also, in Quartz the $\mathrm{Si}-\mathrm{O}$ bond length is shorter than calculates for a single bond which is about $0.161 \mathrm{~nm}$. This indicates a partial double binding character which explains the stability of Quartz.

\section{OUTCOME}

\section{Procedure - Material Selection and Preparation}

The invention outlined describes the preparation of the Nano Porous Ceramic Membrane using the ball mill grinding technique and it is fabricated from the powder of natural solid materials. The procedure is outlined through the flow chart below (figure 3).

Based on experimental results the materials used to create the unique ceramic porous membrane were: Quartz, Feldspar, New Zealand China Clay (NCC), HBC Kaolin, Tai brick, Calcite and Talc.

A mill is a device that breaks solid materials (Quartz, Alumina powder, Talc, Taibac stone) into smaller

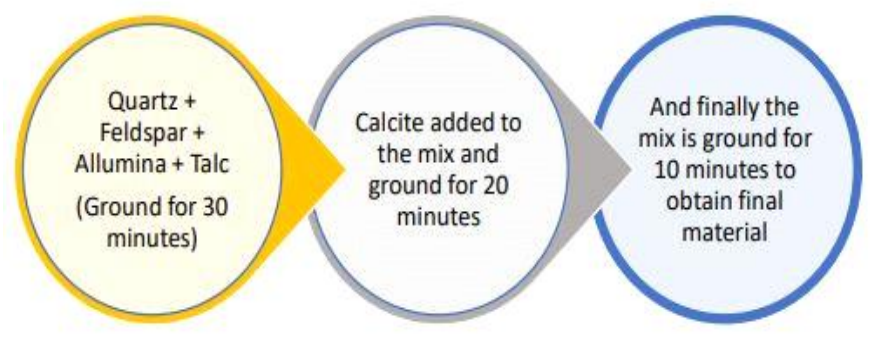

Figure 3 - Process of mixing pieces by grinding, crushing, or cutting. The materials are added in specific percentages and the target pore forming material was Quartz.

Initially the hard materials were ground by the ball mill to break the particle to a size range smaller than that of 8 micrometers $(8 \mu \mathrm{m})$. This procedure generates around $80-90 \%$ of the required particle size. Thereafter Feldspar Dolomite and New Zealand China Clay (NZCC) was ground separately on two occasions.

Feldspar Dolomite was crushed to obtain a required particle size and NZCC was added to it where the new mixture was ground so as to obtain the relevant particle size. Thereby the changes in the material were assessed by varying the temperature, porosity filtration rate, powder particle size, and bending strength of main molecules. Further different materials were also added in different percentages in order to observe the changes that would occur in the final material formed. Then initially and secondly ground mixtures were mixed. 
In order to prevent the materials from sticking together $1 \%$ of sodium silicate deflocculant was added to the second mixture formed. And from the total volume of the mixture, $40 \%$ of the total space filled by the pebbles and void space in pebbles were calculated. The ground raw material was added according to the void space calculated. The raw material: water ratio was maintained at 1: 1.

Once all the materials were mixed a slip was formed. The density of the slip is used to drain the casting. A concaved mold was made and the slip was poured into the mold. This was then dried at $60^{\circ} \mathrm{C}$ for 45 minutes and was kept at room temperature for 24 hours.

\section{Analyzing the membrane density, porosity and the chemical stability of quartz}

As the final product of the membrane material was to consist of specific characteristics and composition suitable as per the research, components in the mix were varied and the product obtained was tested. The materials were selected based on the general composition used for designing ceramic permeable membranes. The highlight of the new composition remained as the substitution of Quartz as the poreforming agent.

One of the experimental procedures initially done was to find the suitability of using Quartz and mixing it with another pore-forming agent such as dolomite brought up queries as to what percentages would provide the finesse material we were looking for. It was experimented by creating materials with a composition where dolomite was increased in

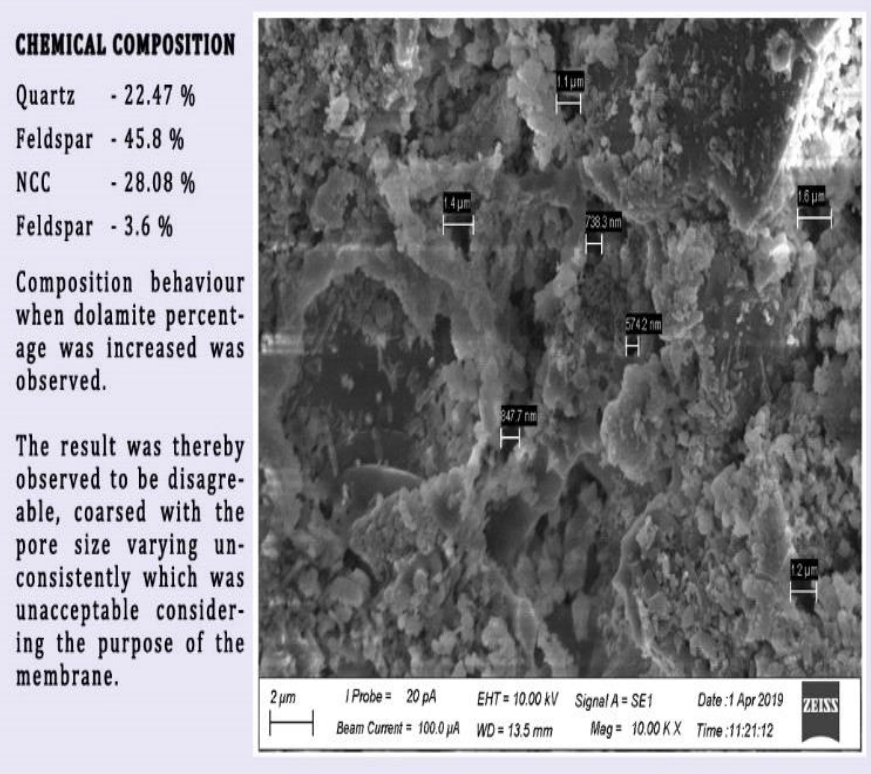

Figure 4-SEM cross sectional image of Dolomite composition percentage while Quartz percentage was reduced but the outcome results as in figure 4 did not align with the desired characteristics we were seeking for.

Thus, the material composition was altered so that the dolomite percentage was reduced to an amount almost inconsiderable yet existed sufficiently for the binding procedures. Further other pore-forming agents such as wood powder was mixed to observe the difference between the material formed and what is desired. The experimental outcomes are depicted in figure 5.

\section{SAMPLE @ 965C}

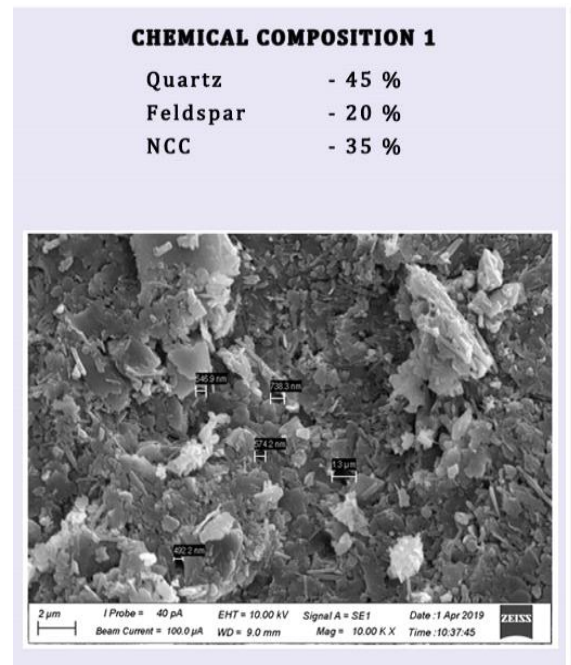

$\begin{array}{ll}\text { CHEMICAL COMPOSITION } 1 \\ \text { Quartz } & -20 \% \\ \text { Dolamite } & -45 \% \\ \text { NCC } & -35 \% \\ \text { Woodpowder } & -100+5 \%\end{array}$

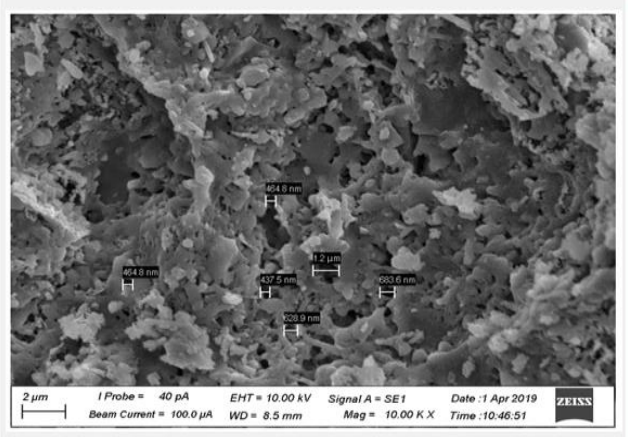

CHEMICAL COMPOSITION 1

Quartz $\quad-20 \%$

Dolamite $\quad-45 \%$

NCC $\quad-25 \%$

Figure 5 - SEM cross sectional image of composition variation at $965^{\circ} \mathrm{C}$ 
The samples were given above in figure 5 were subsequently tested at a given temperature which is $965^{\circ} \mathrm{C}$ thus, only the change in the chemical composition would be the effect of any changes observed. The pores formed with the addition of other materials such as wood powder were inacceptable as constant pore forming and the accuracy of the pore range was not obtained. Further were continued by increasing the temperature with these materials and the outcomes of the permeable membrane were as in figure 6 .

The material began reducing the percentage of pores formed when the temperature was increased. This was reasoned out experimentally through the observation and analysis that with the increasing temperature the material tends to melt in all components thereby losing the porosity

SAMPLE @ 1365C

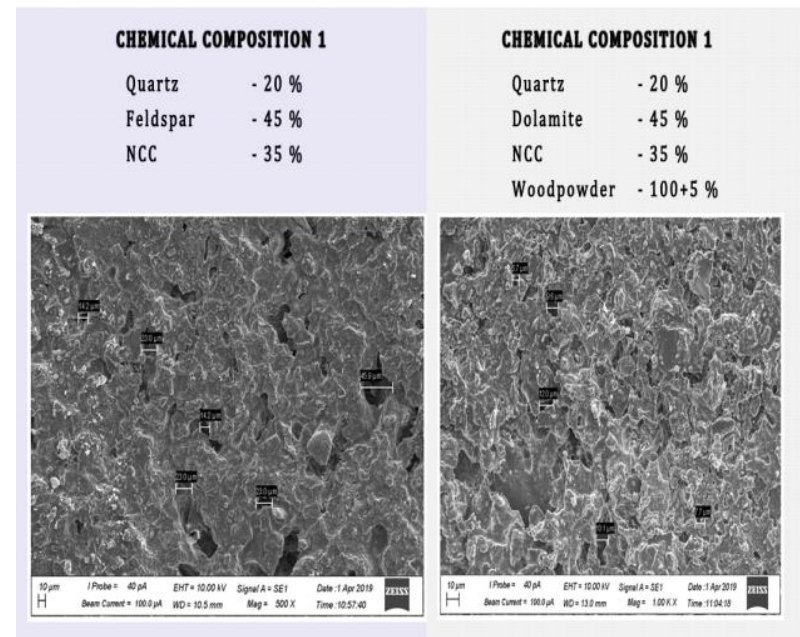

Figure 6-SEM image of composition at increased temperature of the membrane. Where wood powder was added the results were observed to be worse thus the experiments continued maintaining Quartz as the pore-forming agent in all instances and the composition percentages of each component selected were altered for observations. The composition that created the most stable material was derived through the experiments. Thus, the materials used in the final composition can be listed out in percentage as,

$\begin{array}{llll}\text { Quartz } & : 55 \% & \text { Tai } & : 5 \% \\ \text { Feldspar } & : 6 \% & \text { Calcite } & : 2.5 \% \\ \text { NZCC }: 26 \% & \text { Alumina: } 2.5 \% \\ \text { Dolomite }: 2.5 \% & \text { Talc }: 0.5 \%\end{array}$

While the composition was maintained at the given percentages the effects on the material porosity due to the temperature variation were experimented. This was done to clarify the material stability of Quartz based on the findings of its characteristics based on temperature and the phase transition procedures. It was observed that at lower temperatures the membrane formed consisted of inconsistent pores whereas at very high temperatures the porosity appeared to vanish. The best fit temperature was thereby obtained with experimental analytical procedures.

\section{Porosity with Temperature as a Variable}

Experiments were done where the temperature was varied while the material composition was maintained at fixed percentages. The material characteristic behavior and the poreforming ability was observed with the change of the temperature. The temperature was varied from a range of $950^{\circ} \mathrm{C}-1350^{\circ} \mathrm{C}$. Where the most desirable composition with the specified pore size range was obtained at a temperature of $1250^{\circ} \mathrm{C}$ as presented in figure 7 and 8.

The material composition presented with pores of large size range where a certain amount of debris was formed around the pore edges at low temperatures of about $950^{\circ} \mathrm{C}$. This was an

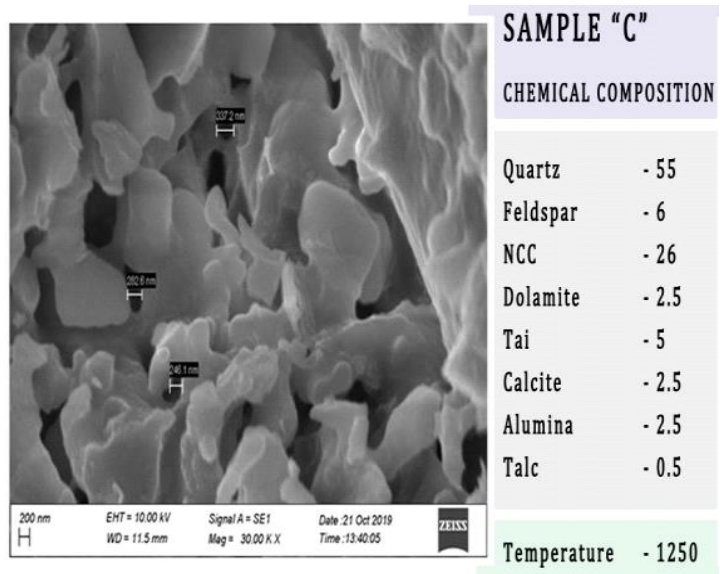

Figure 7 - SEM image: Cross section of final material 
issue and cannot be used as the possibility of unwanted matter mixing with the growth factor could create a medically ethical issue in the procedure.

The fineness of the permeable membrane is therefore a critical factor that needs to be addressed and paid attention to detail for.

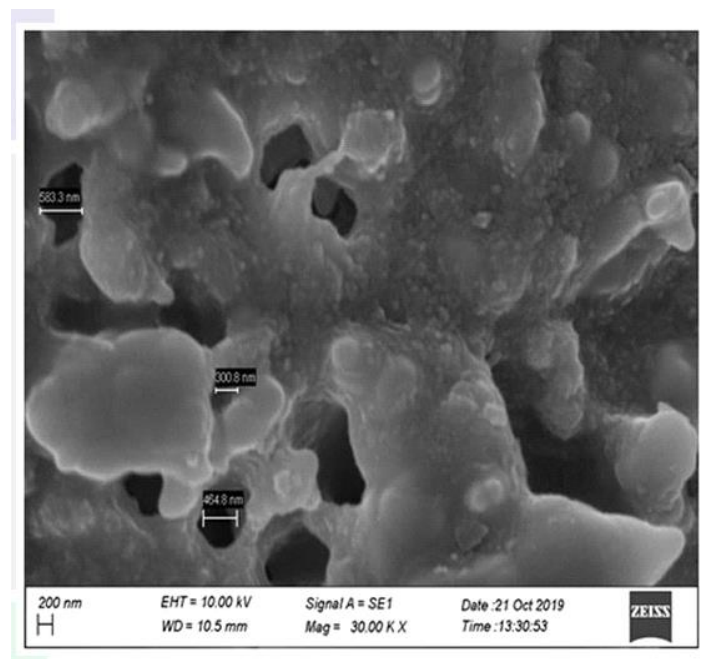

Figure 8 - SEM image: Surface Area of final

\section{Membrane Density Test}

A ceramic disc was immersed in de ionized water for $24 \mathrm{~h}$. The excess water was wiped out with tissue paper so as to keep the area dry. The wet membrane was then weighed and thereafter dried in an oven at $100^{\circ} \mathrm{C}$ for 6 hours. After drying the membrane, the density was calculated according to the equation (1) given below.

$$
\rho=\frac{m_{d r y}}{V}=\frac{m_{d r y}}{\frac{\pi}{4} \cdot d^{2} l}
$$

Where,

- $\rho$ is defined as density $(\mathrm{g} / \mathrm{m} 3)$,

- mdry as weight of dry ceramic disc (g),

- d diameter of sintered disc and

- I thickness of disc.

Membrane density was calculated for all the sample ceramic by using the equation (1). Membrane porosity was evaluated using the "image J" software. This software helps to find a particular range of available pores in sample ceramic.

The morphology of Quartz with the variables was carried out using the Scanning Electron Microscope (SEM). Further, X-Ray diffraction was performed on the designed material to determine their phase compositions analyzing it with the general material characterizations studied as outlined in previous sections.

\section{Chemical Stability Test for the membrane on specific Variables}

Chemical was quantified in terms of mass loss of leaving the ceramic membrane in contact with acid and alkaline solution individually for 24 hours. The weight loss in acid was found to be around $4 \%$ and less whereas weight loss in alkaline was found to be negligible. Result revealed that the membrane exhibits good corrosion resistance in acid and basic media. 


\section{SEM and XRD Studies}

The created ceramic membrane was investigated with the use of XDR an SEM technology so as to study the constituent materials within the material created. The study proved that the material consists of the selected materials which are biocompatible and any other harmful particles such as heavy metals do not exist in the material fabricated.

The readings of the reports can be observed in figure 9 given below obtained from the XRD studies clarifying the inexistence of any heavy metal in the compound.

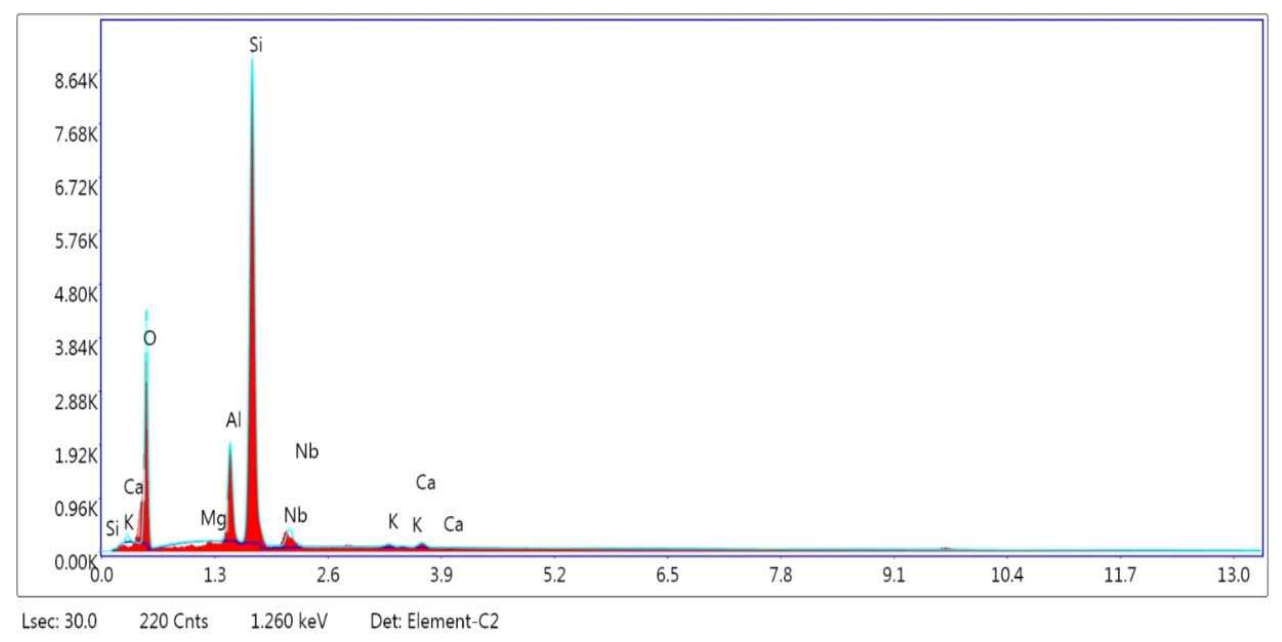

Figure 09-XRD image of final compound

\section{DISCOVERIES}

\section{Discovery of Conical Shaped Pores}

As observed the images given above are cross-sections obtained from the bottom surface of the membrane and the top surface subsequently. The pore formation clearly and coincidently provided results where the lower surface pores remained a constant range of smaller size than that obtained at the top surface. This created a clear conical shape which observed as the outcome. The conical shape was considered as a coincidental finding and a benefit to improve the filtration process.

In order to attain a finer product, the temperature was increased and the characteristic change was observed. With the temperature increasing from $950^{\circ} \mathrm{C}$ observations were made that the pores formed were finer, accurate and within the desired nano size. To observe if the size range could be reduced further and create a better membrane the temperature was increased and observed. With the increasing of the temperature from about $1350^{\circ} \mathrm{C}$ and above the pores started vanishing as the material began to collapse as depicted in figure 10 .

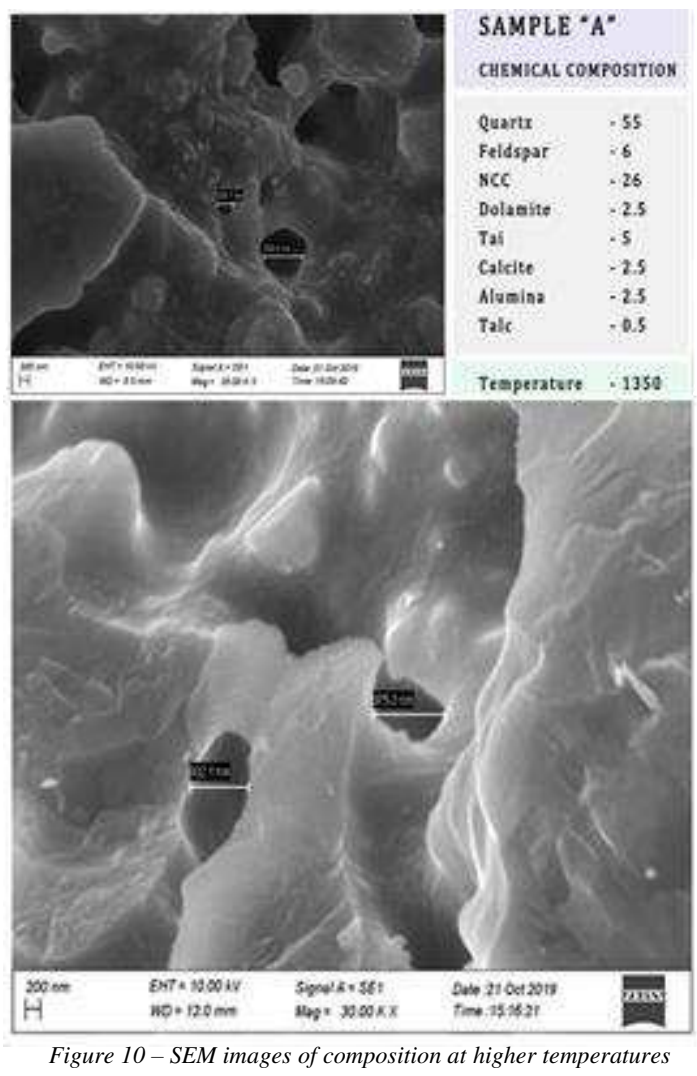


Thus, the overall observations depicted that with the given composition based on the characteristic change with the temperature the material is best applicable for the design when heated at the temperature of $1250^{\circ} \mathrm{C}$. The pores formed at this temperature acquires the size range between $100 \mu \mathrm{m}-200 \mu \mathrm{m}$ and is the applicable size range for the permeable membrane for the medical purpose as per the study done. Those achieved at a slightly lower temperature ranged from $50 \mu \mathrm{m}-200 \mu \mathrm{m}$ in dimension. And at higher temperatures pores sizes of $200 \mu \mathrm{m}-400 \mu \mathrm{m}$ were obtained. But the most applicable size range for the SLNP were studied as those within the range of $100 \mu \mathrm{m}-200 \mu \mathrm{m}$ at a temperature of $1250^{\circ} \mathrm{C}$.

\section{Autologous Components and a Non-Ionic Surfactant}

SLNP can be studied as a core substance essential in the study of nanomedicine and relative treatment procedures. Such Nano Particles (SLNP) are eminent in procedures as encapsulating drugs. The production of SLNP was studied to understand the different methodologies. Each of which is of a rather complex nature. Single emulsion and multiple emulsion are one method used often for SLNP production but contains one of the major issues; the solubilization of the coating material (Heurtault et al., n.d.). Methods incorporating triglyceride containing oils to create nanoparticles are done where the hot lipid phase is dispersed in a surfactant solution and a premix is formed using ultra turrax. After undergoing many cycles, the desired solid lipid particles are formed. (Jenning et al., 2000) Such methods are intricate and of the high cost. The challenge in modern-day medical platform is developing a method to create an easier process to form SLNP for medication procedures that would be cost-effective and biocompatible.

The highlight of the overall study is the formation of the desired SLNP suitable for treatment. For this purpose, the core materials as explained are to be extracted from the patients themselves, stem cells, growth factors, and lipids. The initial procedures thus consist of two main phases which are obtaining the growth factors through the extracted Platelet Rich Plasma (PRP) from the patients' blood and the extraction of abdominal fatty tissues through Liposuction to obtain the adipose- derived stem cells.

The process of obtaining the Growth Factors from the patient initially involves the extraction of the required amount of blood from the patient and centrifuging the retrieved blood. This provides the Platelet Rich Plasma (PRP) through which the harnessed Growth Factors (GF) are then extracted. Subsequently, Abdominal Liposuction is done to extract the fatty tissues from the patients' abdominal walls. The extracted tissues undergo mechanical and enzymatic isolation further providing the Adipose-derived Stem Cells needed. During the process of isolation, Lipid (in liquid form) is formed as a biproduct which in general instances becomes waste material. In this process waste is turned into material used. The lipid obtained is utilized for the formation of the SLNP. The lipids undergo a pressurized filtration through the designed Nanopore ceramic membrane creating the SLNP. Growth Factors and the Adipose-derived Stem Cells are thereafter mixed with a Surfactant to create an aqueous solution for treatment procedures. As previously explained this solution consisting of the autologous components, is introduced into the designed medical contraption where it is mixed with the SLNP by simply shaking the device.

Liposomes in general are known as structures that consist of a hydrophilic core and a hydrophobic bilayer (Gunay, 2018; Ozer, 2018). The phospholipids in this process are the surfactants added. Thus, it is a unique element that the selected surfactant is non-ionic based on its structure and therefore proves the substance to be non-toxic as well as consists of no charge of any sort. The non-ionic structure is advantageous for the treatment procedures in many ways. The substance does not create unnecessary reactions and can be used in any aqueous solution as it does not produce ions when in the solution (Bajpai \& Tyagi, 2010). This allows the substance to compatible with other substances. Research has also proved that the substance has no side effects when introducing to people through treatments and consists of the ability to produce clear stable solutions suitable for even intravenous administrations (Lawrence, 1994). Such studies and outcomes create the opportunity of taking the current study and treatment methods for future developed methods. 


\section{CONCLUSION}

\section{Operating the Device}

The initial procedure consists of two main phases which are obtaining the growth factors through the extracted Platelet Rich Plasma (PRP) from the patients' blood and the extraction of abdominal fatty tissues through Liposuction to obtain the adipose derived stem cells. To create the desired SLNP, the core material used is the lipid obtained from the patient as a by-product during the extraction of adipose derived stem cells. the lipid is thus obtained as a resulting by-product in the form of a liquid state through the process.

The lipids thus obtained in liquid form is what undergoes the membrane contact process at room temperature filtering through the designed ceramic permeable membrane. The aqueous solution including the autologous components (Growth Factors and Stem Cells) is added into the larger compartment which is a 5CC syringe and mixed for emulsification to take place by simply, shaking the device.

\section{End product application}

The final product has been identified to be most suitable for wound treatments. Based on the current studies done the coating layer can be subjected to penetration with enzymes at given conditions external to the body. But for the application of the product for internal treatments where injecting it into the human body will be necessary cannot be allowed at the moment as findings proved that the cell has the probability to expand and create possible blocks within blood vessels which could cause negative outcomes. Further study needs to be carried out in order to proceed using it for internal treatments.

The article thus takes a step to build a new platform in the industry of creating permeable membranes for biomedical purposes, developing simple treatment procedures readily available for patients, and increasing finesse, accuracy in affordable cell treatment procedures. The ability of forming permeable membranes using Quartz as the pore-forming agent creates a next level advancement in material sciences as well as the medical industry. It is a great advantage in the medical industry that membranes with specified permeability can be designed within controlled conditions and an even more advantageous as the final product can be certified as a Bio-Compatible membrane. The ability of creating nano-sized pores in the membrane can be used not only in Solid Lipid Nano Particle (SLNP) treatments but can be modified and used for different filtration procedures and other medical areas that are not being approached yet. The introduction of the new device of low-cost production yet a user-friendly design also has been a highlight within the study. Obtaining the patent for the design has been a solid foundation for its implementation. With the improvement of further detailed studies, the application of the device can even be expanded in the future. Further, the development of a simple procedure in the application of Stem Cell and Growth Cell in wound treatments is believed to create the step forward opening doors for other possibilities such procedures could be applied. Living in an era where personal medical attention and treatment has turned out to be an essential requirement for all, this study can be a guide for many more cell treatment procedures. 


\section{REFERENCES}

1. Abd Aziz, M. H., Othman, M. H. D., Hashim, N. A., Adam, M. R., \& Mustafa, A. (2019). Fabrication and characterization of mullite ceramic hollow fiber membrane from natural occurring ball clay. Applied Clay Science, 177, 51-62. https://doi.org/10.1016/j.clay.2019.05.003

2 Ahmed El-Harati, A., Charcosset, C., \& Fessi, H. (2006). Influence of the Formulation for Solid Lipid Nanoparticles Prepared with a Membrane Contactor. Pharmaceutical Development and Technology, 11(2), 153-157. https://doi.org/10.1080/10837450600561182

3. Alves Xavier, L., de Oliveira, T. V., Klitzke, W., Mariano, A. B., Eiras, D., \& Vieira, R. B. (2019). Influence of thermally modified clays and inexpensive pore-generating and strength improving agents on the properties of porous ceramic membrane. Applied Clay Science, 168, 260-268. https://doi.org/10.1016/j.clay.2018.11.025

4. Bajpai, D., \& Tyagi, V. K. (2010). Nonionic Surfactants: An Overview. Tenside Surfactants Detergents, 47(3), 190-196. https://doi.org/10.3139/113.110062

5. Ben Ali, M., Hamdi, N., Rodriguez, M. A., Mahmoudi, K., \& Srasra, E. (2018). Preparation and characterization of new ceramic membranes for ultrafiltration. Ceramics International, 44(2), 2328-2335. https://doi.org/10.1016/j.ceramint.2017.10.199

6. Bernardo, P., \& Drioli, E. (2010). Membrane Technology: Latest Applications in the Refinery and Petrochemical Field. In Comprehensive Membrane Science and Engineering (pp. 211-239). Elsevier. https://doi.org/10.1016/B978-0-08-093250-7.00054-2

7. Blatt, H. (1987). Perspectives; Oxygen isotopes and the origin of quartz. Journal of Sedimentary Research, 57(2), 373-377. https://doi.org/10.1306/212F8B34-2B24-11D7-8648000102C1865D

8. Canals, M., \& Meunier, J. D. (1995). A model for porosity reduction in quartzite reservoirs by quartz cementation. Geochimica et Cosmochimica Acta, 59(4), 699-709. https://doi.org/10.1016/00167037(94)00355-P

9. Charcosset, C., El-Harati, A., \& Fessi, H. (2005). Preparation of solid lipid nanoparticles using a membrane contactor. Journal of Controlled Release, 108(1), 112-120. https://doi.org/10.1016/j.jconrel.2005.07.023

10. Crawford, B. R., Faulkner, D. R., \& Rutter, E. H. (2008). Strength, porosity, and permeability development during hydrostatic and shear loading of synthetic quartz-clay fault gouge. Journal of Geophysical Research, 113(B3), B03207. https://doi.org/10.1029/2006JB004634

11. de Vreede, L. J., van den Berg, A., \& Eijkel, J. C. T. (2015). Nanopore Fabrication by Heating Au Particles on Ceramic Substrates. Nano Letters, 15(1), 727-731. https://doi.org/10.1021/nI5042676

12. Falcon-Suarez, I., \& Canal, J. (2013). Techniques for rock permeability determination II. The pore pressure oscillation method. https://doi.org/10.13140/RG.2.1.4493.7208

13. Garud, A., Singh, D., \& Garud, N. (2012). Solid Lipid Nanoparticles (SLN): Method, Characterization and Applications. International Current Pharmaceutical Journal, 1(11), 384-393. https://doi.org/10.3329/icpj.v1i11.12065

14. HnrvrrNcwlv, B. S. (n.d.). Quartz: Heat capacitiesfrom 340 to $1000 \mathrm{~K}$ and revisedvaluesfor the thermodynamicproperties. 7.

15. Jenning, V., Thünemann, A. F., \& Gohla, S. H. (2000). Characterisation of a novel solid lipid nanoparticle carrier system based on binary mixtures of liquid and solid lipids. International Journal of Pharmaceutics, 199(2), 167-177. https://doi.org/10.1016/S0378-5173(00)00378-1 
16. Kilikoglou, V., Vekinis, G., Maniatis, Y., \& Day, P. M. (1998). MECHANICAL PERFORMANCE OF QUARTZTEMPERED CERAMICS: PART I, STRENGTH AND TOUGHNESS. Archaeometry, 40(2), 261-279. https://doi.org/10.1111/j.1475-4754.1998.tb00837.x

17. Lawrence, M. J. (1994). Surfactant systems: Their use in drug delivery. Chemical Society Reviews, 23(6), 417. https://doi.org/10.1039/cs9942300417

18. Lee, H. J., Kim, M. K., Park, J. H., \& Magnone, E. (2020). Temperature and pressure dependence of the $\mathrm{CO} 2$ absorption through a ceramic hollow fiber membrane contactor module. Chemical Engineering and Processing - Process Intensification, 150, 107871. https://doi.org/10.1016/j.cep.2020.107871

19. Li, H. C., \& De Bruyn, P. L. (1966). Electrokinetic and adsorption studies on quartz. Surface Science, 5(2), 203-220. https://doi.org/10.1016/0039-6028(66)90082-3

20. Li, J., Li, L., Zheng, L., Xian, Y., \& Jin, L. (2006). Determination of chemical oxygen demand values by a photocatalytic oxidation method using nano-TiO2 film on quartz. Talanta, 68(3), 765-770. https://doi.org/10.1016/j.talanta.2005.06.012

21. Mancktelow, N. S., Grujic, D., \& Johnson, E. L. (1998). An SEM study of porosity and grain boundary microstructure in quartz mylonites, Simplon Fault Zone, Central Alps. Contributions to Mineralogy and Petrology, 131(1), 71-85. https://doi.org/10.1007/s004100050379

22. Motte, F., Falcoz, Q., Veron, E., \& Py, X. (2015). Compatibility tests between Solar Salt and thermal storage ceramics from inorganic industrial wastes. Applied Energy, 155, 14-22. https://doi.org/10.1016/j.apenergy.2015.05.074

23. Mouiya, M., Bouazizi, A., Abourriche, A., Benhammou, A., El Hafiane, Y., Ouammou, M., Abouliatim, Y., Younssi, S. A., Smith, A., \& Hannache, H. (2019). Fabrication and characterization of a ceramic membrane from clay and banana peel powder: Application to industrial wastewater treatment. Materials Chemistry and Physics, 227, 291-301. https://doi.org/10.1016/j.matchemphys.2019.02.011

24. Ozgumus, T., Mobedi, M., \& Ozkol, U. (2014). Determination of Kozeny Constant Based on Porosity and Pore to Throat Size Ratio in Porous Medium with Rectangular Rods. Engineering Applications of Computational Fluid Mechanics, 8(2), 308-318. https://doi.org/10.1080/19942060.2014.11015516

25. Peng, Z., \& Redfern, S. A. T. (2013). Mechanical properties of quartz at the $\alpha-\beta$ phase transition: Implications for tectonic and seismic anomalies: QUARTZ AT THE $\alpha-\beta$ PHASE TRANSITION. Geochemistry, Geophysics, Geosystems, 14(1), 18-28. https://doi.org/10.1029/2012GC004482

26. Rosenbrand, E. (n.d.). Effect of temperature on sandstone permeability. 253.

27. Shazly, G. A. (2017). Ciprofloxacin Controlled-Solid Lipid Nanoparticles: Characterization, In Vitro Release, and Antibacterial Activity Assessment. BioMed Research International, 2017, 1-9. https://doi.org/10.1155/2017/2120734

28. Silindir-Gunay, M., \& Ozer, A. Y. (2018). Liposomes and micelles as nanocarriers for diagnostic and imaging purposes. In Design of Nanostructures for Theranostics Applications (pp. 305-340). Elsevier. https://doi.org/10.1016/B978-0-12-813669-0.00008-7

29. Spearing, D. R., Farnan, I., \& Stebbins, J. F. (n.d.). Dynamics of the Phase Transitions in Quartz and Cristobalite as Observed by In-Situ High Temperature 29Si and 170 NMR. 15.

30. Stevens, R. L. (1991). Grain-size distribution of quartz and feldspar extracts and implications for flocculation processes. Geo-Marine Letters, 11(3-4), 162-165. https://doi.org/10.1007/BF02431004 
31. Wang, H., Rezaee, R., \& Saeedi, A. (2015). The High Temperature Effects on Pore Size Distribution of Tight Sandstone: An Application of Microwave Heating in Enhanced Gas Recovery (EGR). SPE/IATMI Asia Pacific Oil \& Gas Conference and Exhibition. SPE/IATMI Asia Pacific Oil \& Gas Conference and Exhibition, Nusa Dua, Bali, Indonesia. https://doi.org/10.2118/176264-MS

32. Wu, P., Xu, Y., Huang, Z., \& Zhang, J. (n.d.-a). Ceramic Processing Research. 5.

33. Wu, P., Xu, Y., Huang, Z., \& Zhang, J. (n.d.-b). Ceramic Processing Research. 5.

34. Youmoue, M., Fongang, R. T. T., Sofack, J. C., Kamseu, E., Melo, U. C., Tonle, I. K., Leonelli, C., \& Rossignol, S. (2017). Design of ceramic filters using Clay/Sawdust composites: Effect of pore network on the hydraulic permeability. Ceramics International, 43(5), 4496-4507. https://doi.org/10.1016/j.ceramint.2016.12.101

35. Zhang, J. Q., Liu, J., Li, X. L., \& Jasti, B. R. (2007). Preparation and Characterization of Solid Lipid Nanoparticles Containing Silibinin. Drug Delivery, 14(6), 381-387. https://doi.org/10.1080/10717540701203034

36. Zhitomirsky, B., Yunaev, A., Kreiserman, R., Kaplan, A., Stark, M., \& Assaraf, Y. G. (2018). Lysosomotropic drugs activate TFEB via lysosomal membrane fluidization and consequent inhibition of mTORC1 activity. Cell Death \& Disease, 9(12), 1191. https://doi.org/10.1038/s41419-018-1227-0 


\section{Figures}

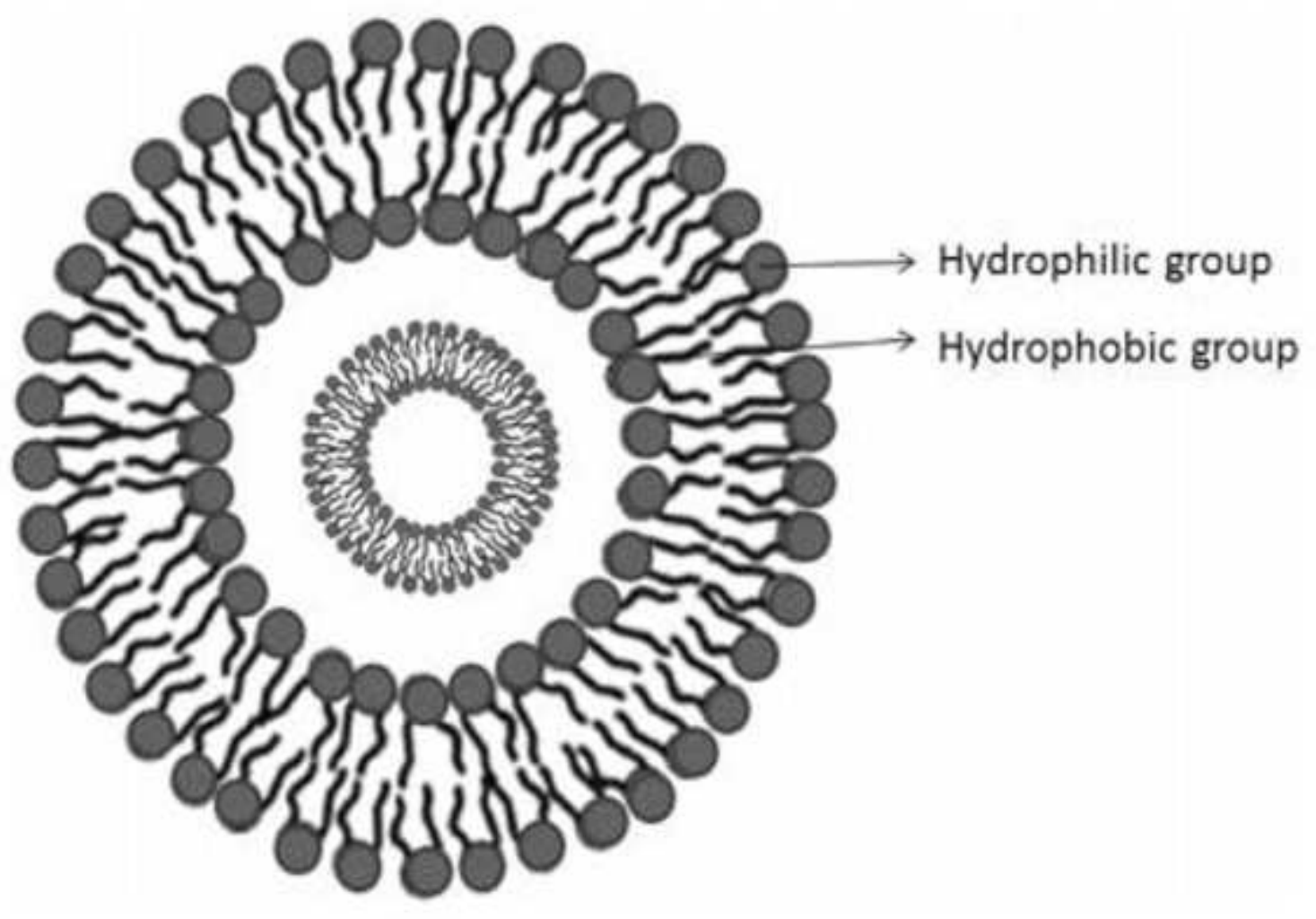

Figure 1

Hypothetical structure of Liposomic structural Solid Lipid Nano Particle

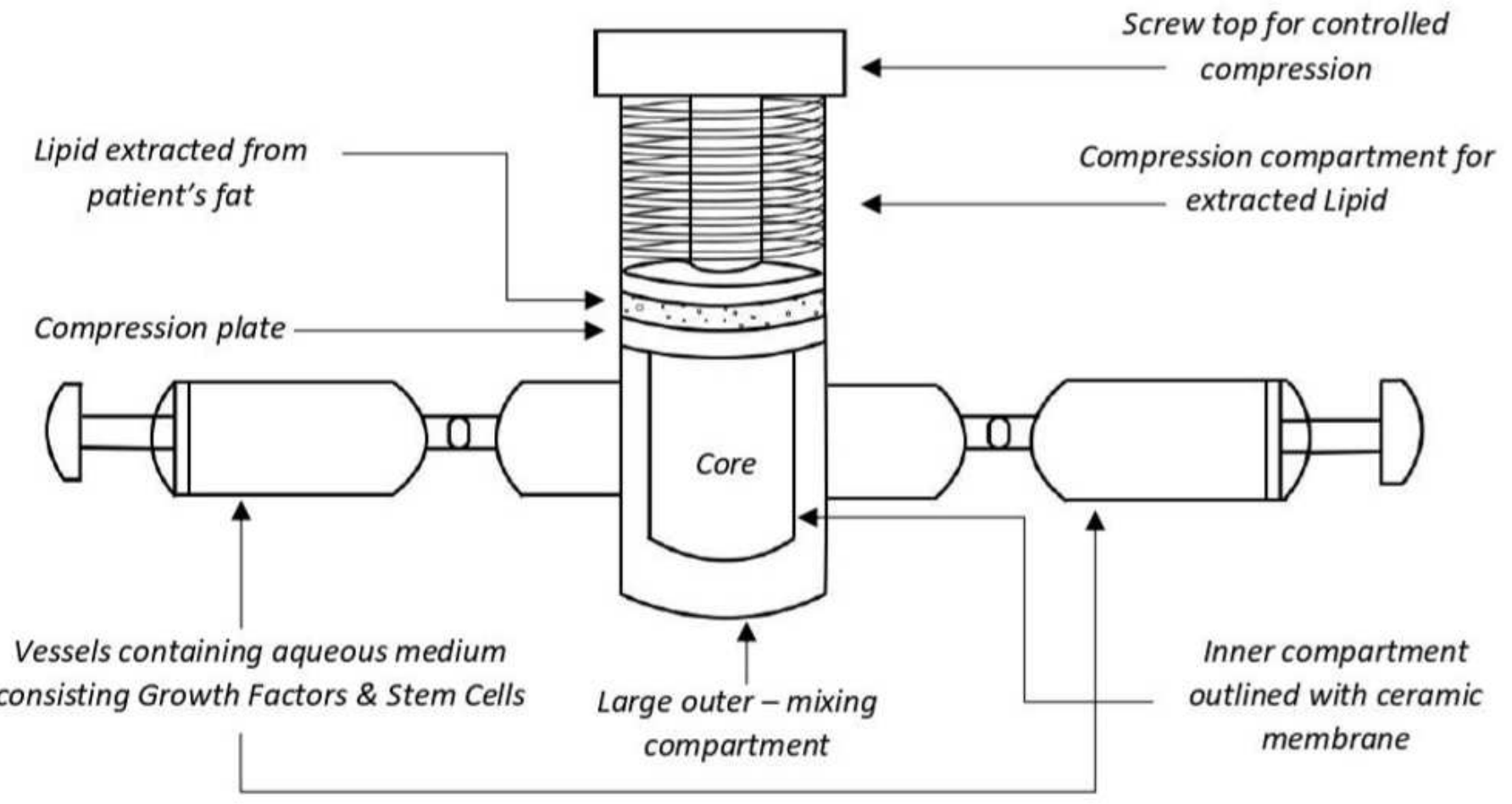


Figure 2

Invented devise (line diagram)

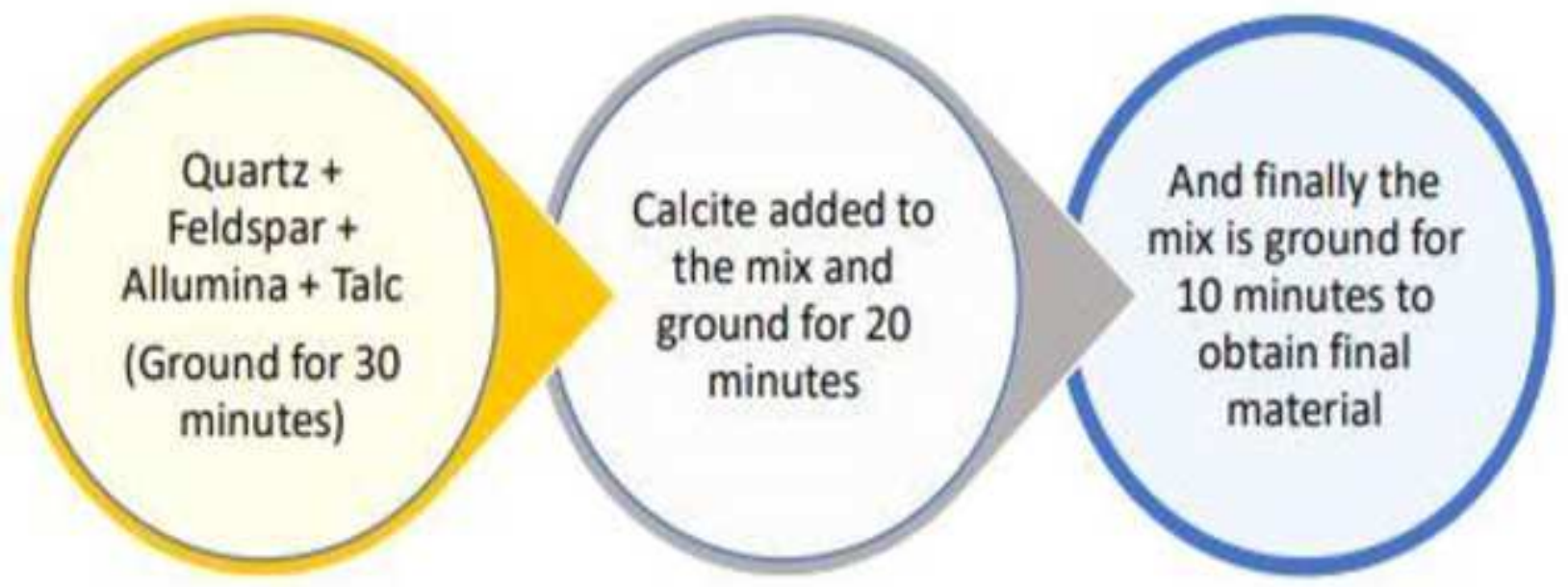

Figure 3

Process of mixing

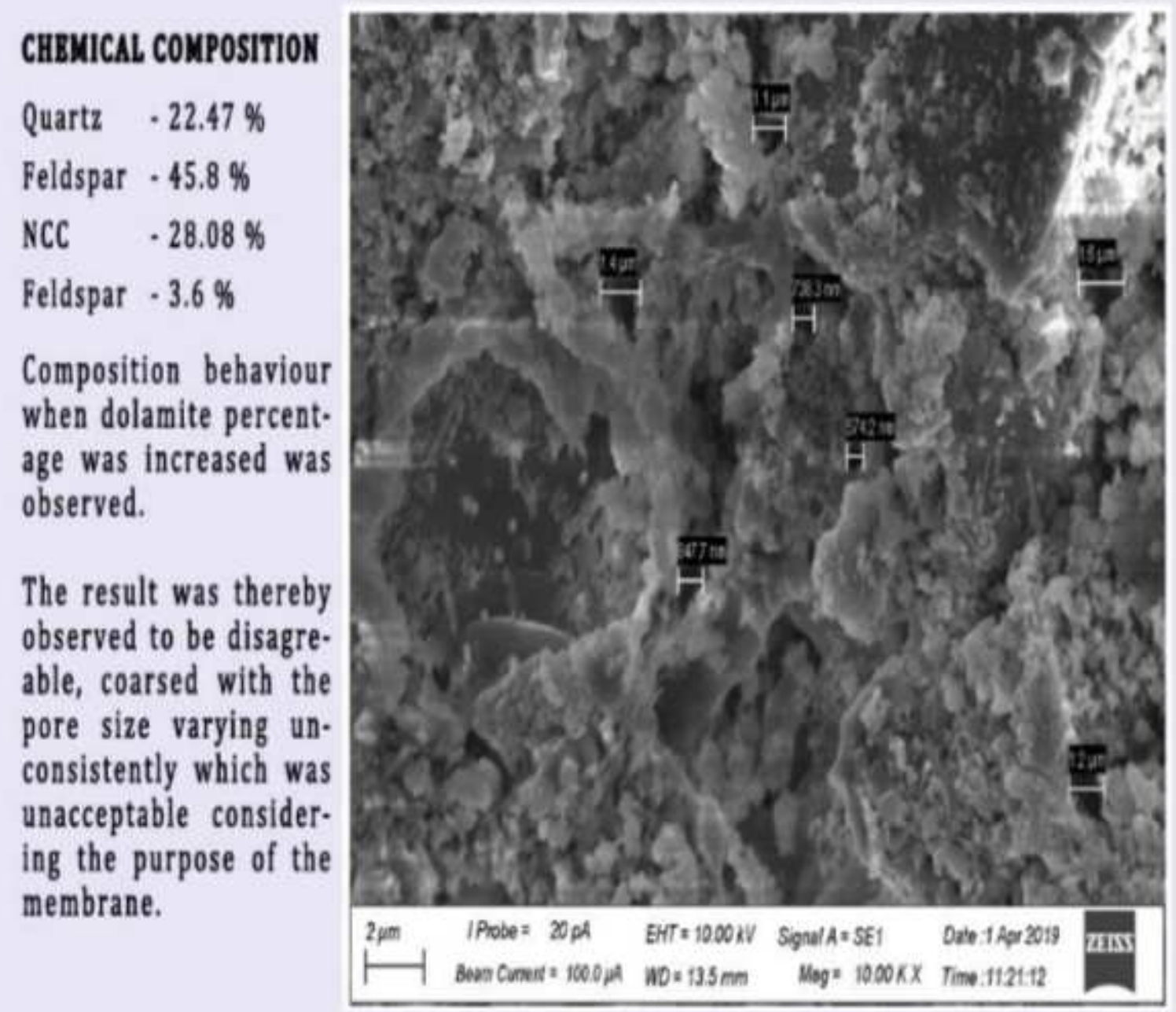


Figure 4

SEM cross sectional image of Dolomite composition

\section{SAMPLE @ 965C}
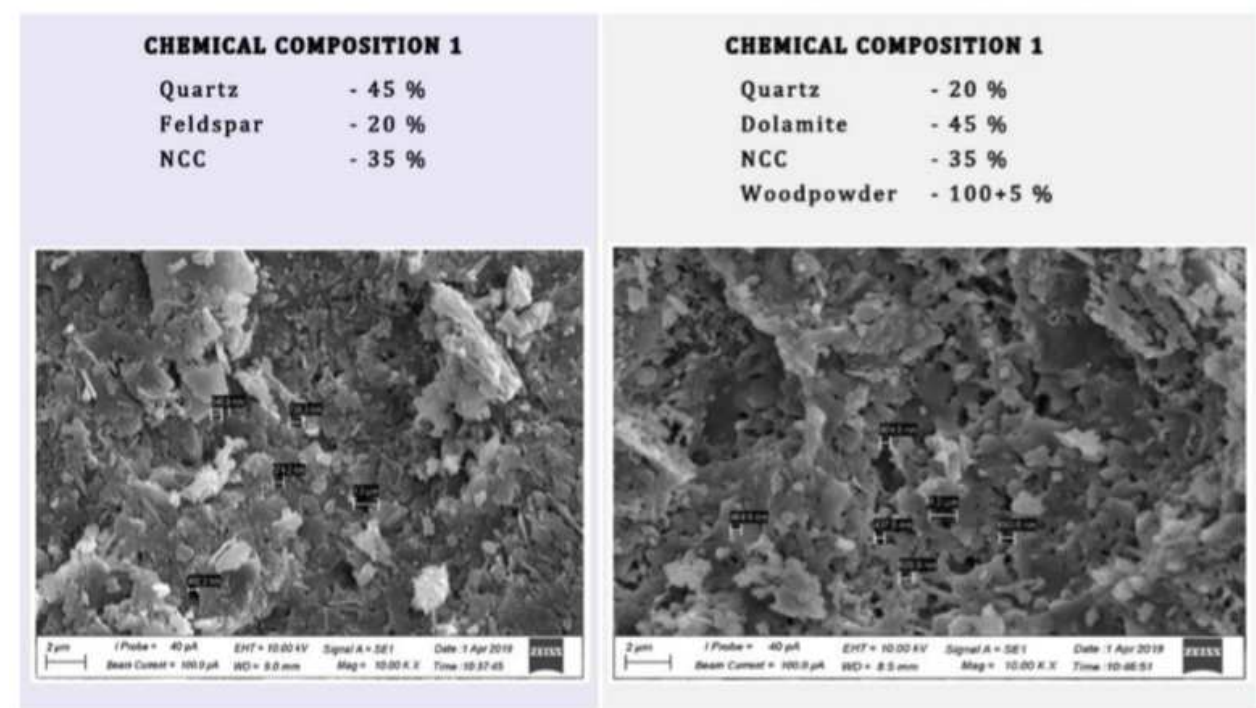

CHEMICAL COMPOSITION 1

$\begin{array}{ll}\text { Quartz } & -20 \% \\ \text { Dolamite } & -45 \% \\ \text { NCC } & -25 \%\end{array}$

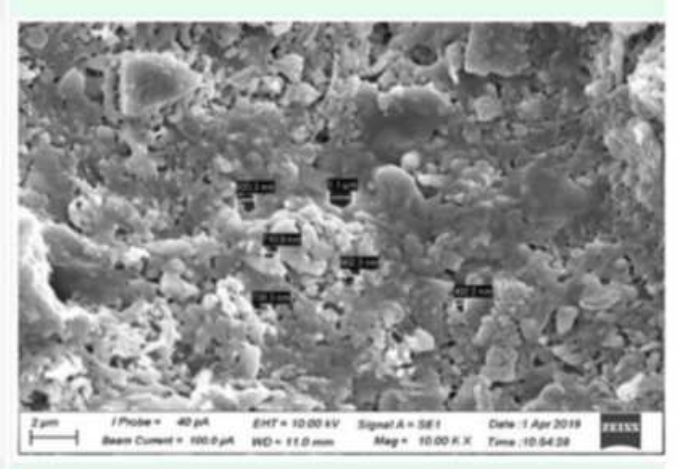

Figure 5

SEM cross sectional image of composition variation at $965 \mathbb{} \mathrm{C}$ 


\section{SAMPLE @ 1365C}

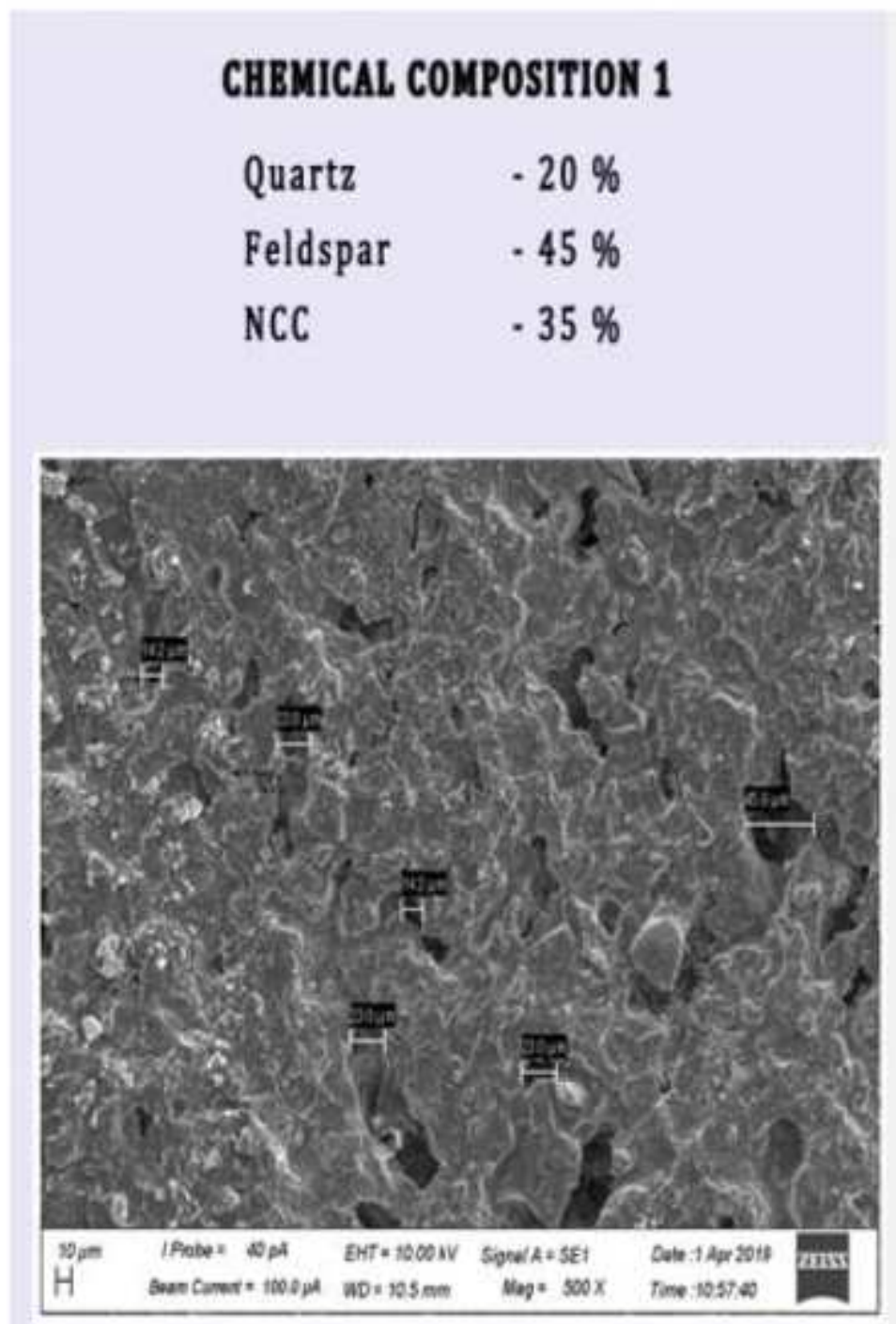

CHEMICAL COMPOSITION 1

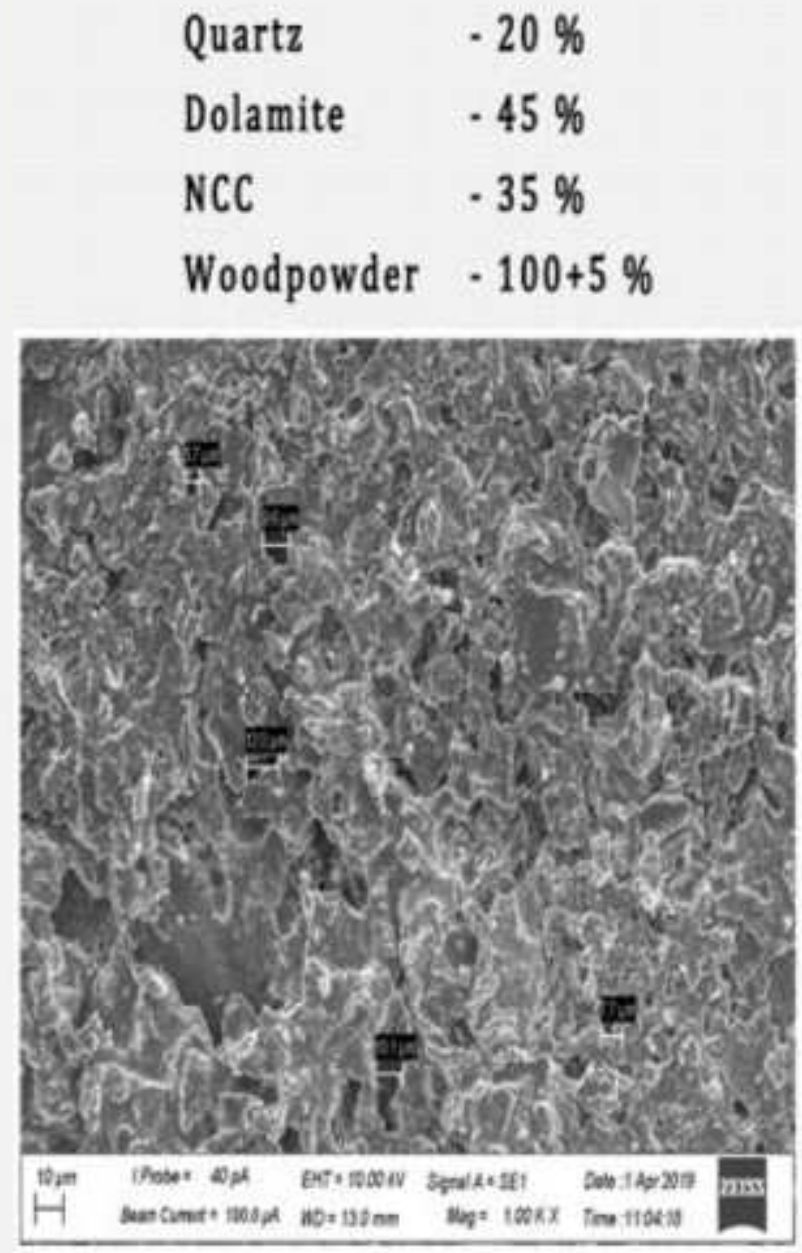

Figure 6

SEM image of composition at increased temperature 


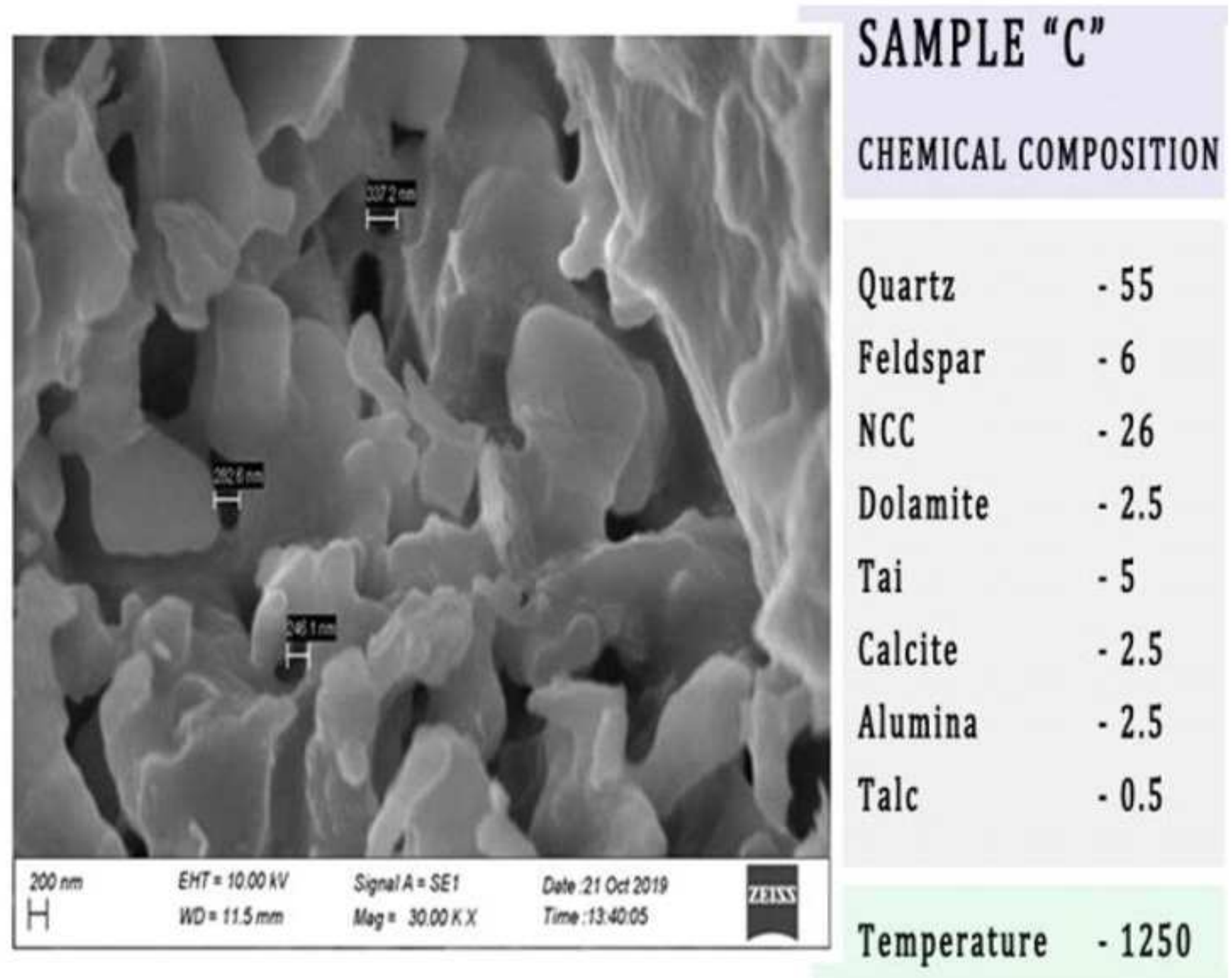

Figure 7

SEM image: Cross section of final material 


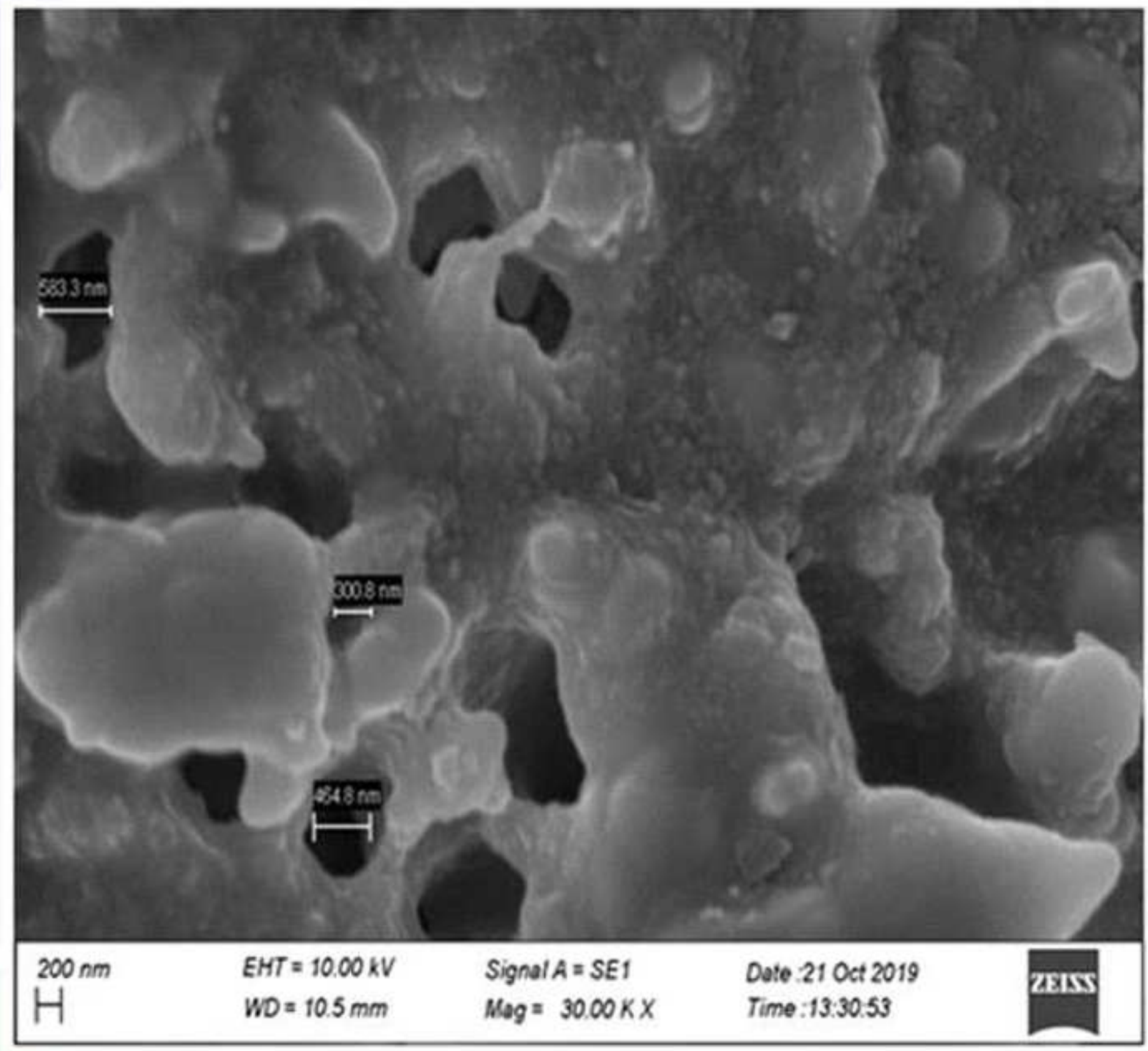

Figure 8

SEM image: Surface Area of final 


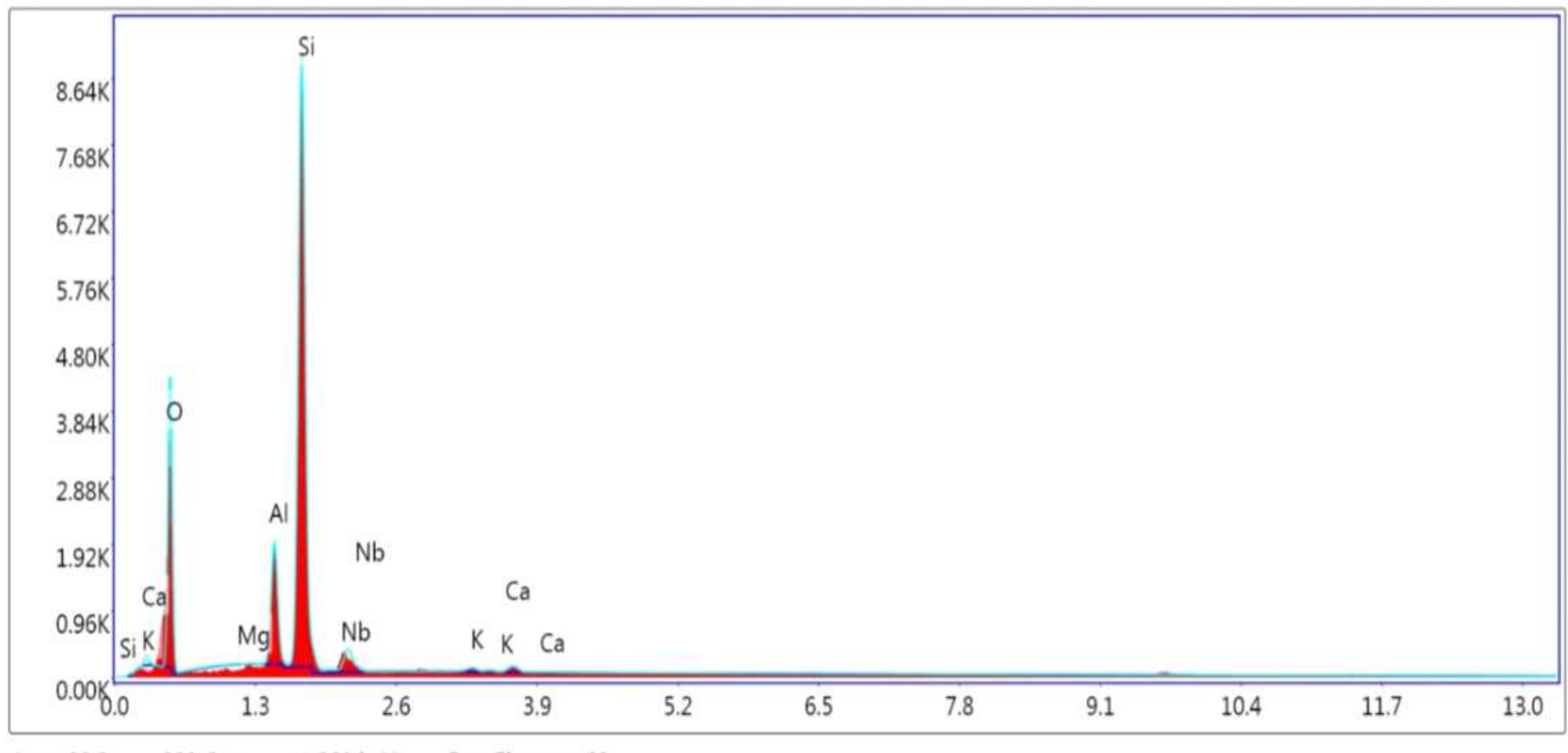

Lsec: $30.0 \quad 220$ Cnts $\quad 1.260 \mathrm{keV}$ Det: Element-C2

Figure 9

XRD image of final compound 


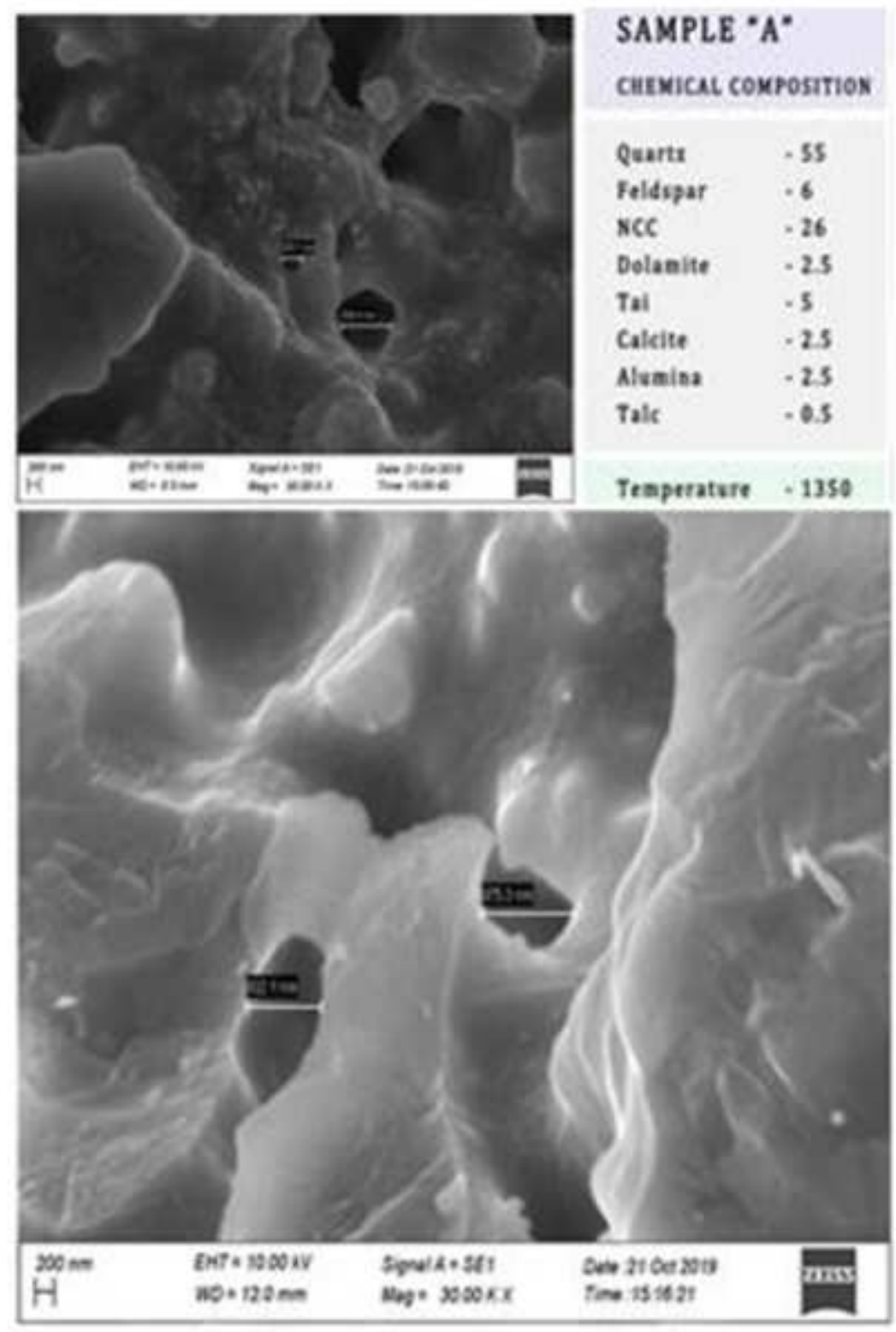

Figure 10

SEM images of composition at higher temperatures 